Molecular structure

Elsevier Editorial System(tm) for Journal of Manuscript Draft

Manuscript Number: MOLSTRUC-D-18-03618R1

Title: The mineralization effect on chitosan hydrogel structure containing collagen and alkaline phosphatase

Article Type: Research Paper

Keywords: chitosan; hydrogels; collagen; alkaline phosphatase Corresponding Author: Dr. Agata Lilia Skwarczynska, Ph.D.

Corresponding Author's Institution: Rzeszow University of Technology

First Author: Agata Lilia Skwarczynska, Ph.D.

Order of Authors: Agata Lilia Skwarczynska, Ph.D.; Dorota Binias;

Waldemar Maniukiewicz; Zofia Modrzejewska; Timothy Douglas 
I would like to take the opportunity to thank to the reviewers for insightful comments and respond in detail to each of the comments made by the reviewers in the space provided.

\section{Reviewer \#1:}

In this report, the authors described the synthesis of chitosan based hydrogel that contains the collagen and alkaline phosphatase. The subsequent mineralization on these hydrogel was also evaluated. The samples were characterized by FT-IR, XPS and SEM. Moreover, the effects of collagen and alkaline phosphatase on the formation of calcium phosphate was also evaluated. This work is well conducted and organized. It is fully fulfilled the scope of Journal. Therefore, I recommond the acceptance after the following issues were completely addressed.

\section{Apart from the FT-IR, XPS and SEM, other characterization data such as XRD and TGA of the hydrogel before and after mineralization should be provided.}

Thermogravimetric analysis TGA were not provided due to the current lack of such equipment. Authors will include TGA characterization data in further publications.

$\mathrm{X}$ - ray diffraction (XRD) patterns were done for this study and obtained results and discussion are presented in revised version of this article. XRD diffraction patterns before (B) and after (A) mineralization for chitosan gel (1) and for chitosan gel containing collagen $0.5 \mathrm{ml}$ (2) and $1.0 \mathrm{ml}$ (3) respectively were presented in Figure 3. XRD diffraction patterns before (B) and after (A) mineralization for chitosan gel (1); chitosan-collagen $1.0 \mathrm{ml}$ gel (2); chitosan-ALP gel (3) and chitosan-collagen-ALP (4) gel respectively were presented in Figure 8.

Briefly, in the gels with collagen after mineralization, two main bands are observed at an angle of $2 \theta 13^{\circ}$ and $20^{\circ}$ which are associated with chitosan, whereas $26^{\circ}$ may be derived from a calciumphosphate compound. In collagen and ALP gels after mineralization, these bands disappear, while the analysis of XPS spectra shows that the amount of calcium and phosphorus is sagnificantly higher than in the sample of chitosan-collagen gels with ALP.

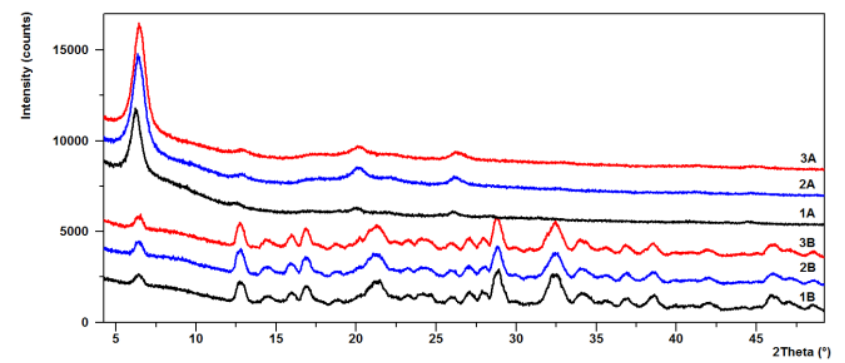

Figure 3. XRD diffraction patterns before (B) and after (A) mineralization for chitosan gel (1) and for chitosan gel containing collagen $0.5 \mathrm{ml}(2)$ and $1.0 \mathrm{ml}(3)$ respectively

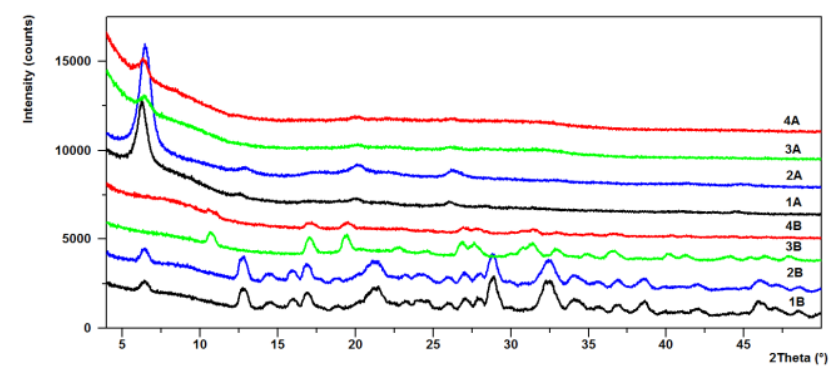


Figure 8. XRD diffraction patterns before $(B)$ and after $(A)$ mineralization for chitosan gel (1); chitosan-collagen $1.0 \mathrm{ml}$ gel (2); chitosan-ALP gel (3) and chitosan-collagen-ALP(4) gel respectively

2.The structure and property of these hydrogel and their mineralization composites have been well characterized, however, the potential applications of these materials have not evaluated or at least discussed.

In this study hydrogels were fabricated and evaluated by determining its structural changes after mineralization for biomedical applications as a scaffolds for bone regeneration. The practical application was included in the introduction section and also in the conclusions section.

3. The quality of many figures is rather poor, all of them must significantly improved before publication.

As suggested all FTIR figures and its captures have been significantly improved and also XRD figures and captions were added.

4. The rheology analyses such as storage modulus and loss modulus of the hydrogel before and after mineralization should be determined.

According to chitosan-collagen gels with ALP after mineralization - the rheological studies are currently conducted and will be published in a separate article in the future.

The current rheological tests of chitosan gels carried out by the authors were presented in the following articles:

Rheological studies for chitosan gels with and without collagen were published in Journal Progress in the Chemistry and Application of Chitin and its Derivatives by co-author Z.Modrzejewska et.al "The influence of the addition of collagen on the rheological properties of chitosan chloride solutions" doi.10.15259/PCACD.22.18

Rheological studies for chitosan gels with and without ALP were previously studied and published by co-authors T.E.L.Douglas, A.Skwarczynska, Z.Modrzejewska et. al "Acceleration of gelation and promotion of mineralization of chitosan hydrogels by alkaline phosphatise" doi.org/10.1016/j.ijbiomac.2013.02.002

Chitosan colloidal systems, created by dispersing in aqueous solutions of hydrochloric acid, with and without the addition of disodium $\beta$-glycerophosphate were previously published by co-author Z.Modrzejewska et. al. in Polymers "Rheo-Kinetic Study of Sol-Gel Phase Transition of Chitosan Colloidal Systems" doi.org/10.3390/polym10010047

5. The toxicity of the hydrogel and their composites with calcium phosphate should be determined at least at the cellular level. The cell viability value could be based on the typical assays (e.g. Toxicology Research 1 (1), 62-68 or Toxicology Research 4 (1), 160-168).

Biological tests were carried out and published by co-authors Z.Modrzejewska et. al. in Journal of Bioactive and Compatible Polymers "Thermosensitive chitosan gels containing calcium glycerophosphate for bone cell culture" doi.org/10.1177/0883911516671150 
Biological properties of the thermosensitive chitosan hydrogels prepared with the use of chitosan chloride with $\beta$-glycerophosphate disodium salt pentahydrate enriched with calcium glycerophosphate were presented and compared with chitosan hydrogels with $\beta$-glycerophosphate disodium salt pentahydrate. The study was focused on the determination of hydrogel structure and biological testing of hydrogels with human osteoblasts line Saos-2.

Moreover another biological studies of thermosensitive chitosan chloride gels with $\beta$ - glycerophosphate disodium was investigated by contact with bone cells (line Saos- 2) for 7 and 21 days. The cells were encapsulated and seeded onto the gel. A live/dead test showed no cytotoxic reaction and published in Applied Polymer Science "The structural (FTIR, XRD, and XPS) and biological studies of thermosensitive chitosan chloride gels with $\beta$ - glycerophosphate disodium" by co-authors A. Skwarczynska and Z. Modrzejewska et al.

Further biological studies and investigations are strictly planned in the next research steps.

6. The mussel-inspired chemistry is an important method for fabrication of functional materials for different applications especially in the biomedical field. The previous reviews and reports (e.g. Chemical reviews 114 (9), 5057-5115, Nanoscale 8 (38), 16819-16840, Biomacromolecules, 2018, $19(6), 1858$-1868) also suggested that the polydopamine could be used for preparation of hydrogel and mineralization for biomedical applications. Some related references (e.g. Nanoscale 4 (18), 5581-5584, Applied Surface Science 343, 19-27, Journal of Materials Chemistry B 3 (17), 3476-3482, Materials Science and Engineering: C 77, 972-977, Applied Surface Science 419, 35-44) about mussel-inspired chemistry should be mentioned and discussed in the revised manuscript.

Regarding to reviewer suggestions mussel-inspired chemistry was included in the text and cited.

\section{Reviewer \#2:}

In the present manuscript, Skwarczynska and coworkers analyzed the influence of enzymatic mineralization induced by alkaline phosphatase (ALP) on the structural properties of thermosensitive chitosan-collagen gels, using a combination of FTIR and XPS spectra as well as SEM images. The obtained data were compared with those previously published concerning the structure of chitosan-collagen gels before mineralization. In particular, the authors investigated the effect of collagen on the structural properties of thermosensitive chitosan gels and the influence of ALP on the structural properties of chitosan and chitosan-collagen gels, before and after mineralization. It turns out that:

* Mineralization induces similar changes in the supermolecular structure of chitosan and chitosan-collagen gels

* Collagen and chitosan are connected through $\mathrm{C} 1$ carbon, amine and hydroxide groups

* During the mineralization process, CaGP is decomposed by ALP to Ca and P

* After mineralization, chitosan-collagen gels containing ALP contain five times more Ca than chitosan hydrogels containing ALP $(8.3 \%$ vs $1.7 \%)$ and the $\mathrm{Ca} / \mathrm{P}$ ratio is closer to that of hydroxyapatite.

The present manuscript addresses an interesting topic and the approach used by the authors is consistent with the aim of the paper. Overall, the FTIR, XPS and SEM images experiments were well performed and provided sound and interesting data. Hence, the scope and content of the manuscript match those of Journal of Molecular Structure. Nonetheless, the obtained data are 
reported and discussed rather confusedly, thus making the manuscript really hard to follow. Moreover, some sentences are not clearly understandable. Therefore, in my opinion the present manuscript by Skwarczynska and coworkers requires major revision to be published in Journal of Molecular Structure.

1. The analysis of the NIR (Pages 8-10) and XPS spectra (Pages 14-15) is really hard to follow. In my opinion, both sections should be rewritten and shortened. This would greatly increase the understandability of the results obtained. As an example, the two paragraphs corresponding to Lines 14-32 of Page 9 could be mergedin a single, shorter paragraph.

2. In my opinion, inclusion in the text of more frequent references to Figures 1-6 would simplify the understanding of the NIR and XPS data.

3. The text contains many sentences whose overall meaning is unclear (see for example Lines 10-12 and Lines 45-46 of Page 5; Lines 11-13, 23, 31-33, 41-47 Page 8; Lines 9-11 of Page 10, Lines 38-39 of Page 14; Lines 13-15 of Page 17).

4. Page 10, Lines 12-14, and Page 17, Lines 1-3. The authors should clearly explain which are the experimental evidences supporting their statement that "An increase of ALP concentrations causes the separation of macromolecules, thus releasing them from the strong mutual deformations".

5. Page 16, Lines 38-42. The meaning of the whole paragraph is rather unclear to me. In my opinion, the authors should explain the following statements

a. "the internal structure of ALP-containing gels that is greatly expanded"

b. "The structure of gels containing collagen and ALP is compressed compared to the structure of gels without ALP".which in the present form are rather unclear.

6. The text contains several typos that should be corrected.

Regarding to reviewer suggestions the results and discussion section was shortened and mend, unclear sentences were improved, typos were removed and corrections have been done. 


\title{
THE MINERALIZATION EFFECT ON CHITOSAN HYDROGEL STRUCTURE CONTAINING COLLAGEN AND ALKALINE PHOSPHATASE
}

\author{
Agata L. Skwarczynska1, Dorota Binias², Waldemar Maniukiewicz ${ }^{3}$, \\ Zofia Modrzejewska ${ }^{4}$, Timothy E.L. Douglas ${ }^{5}$ \\ ${ }^{1}$ Department of Civil, Environmental Engineering and Architecture, Rzeszow University of Technology, \\ Powstancow Warszawy 6, 35-959, Rzeszow, Poland \\ ${ }^{2}$ Institute of Textile Engineering and Polymer Materials, University of Bielsko-Biala, \\ Willowa 2, 43-309 Bielsko-Biala, Poland \\ ${ }^{3}$ Institute of General and Ecological Chemistry, Lodz University of Technology, \\ Zeromskiego 116, 90-924, Lodz, Poland \\ ${ }^{4}$ Department of Environmental Systems Engineering, Faculty of Process and Environmental Engineering, \\ Lodz University of Technology, Wolczanska 213, 90-924, Lodz, Poland \\ ${ }^{5}$ Engineering Department, Lancaster University, Gillow Avenue, Lancaster University, Bailrigg, \\ LA1 4YW, United Kingdom
}

\begin{abstract}
Introducing collagen the basic ingredient of bone tissue into the structure of chitosan gels that are formed at physiological body temperature, aims to create so-called biomimetic structures, which are close in composition to the natural composition of bone tissue. The aim of this study was to determine the influence of mineralization on the structural properties of thermosensitive chitosan-collagen gels containing alkaline phosphatase (ALP) by SEM, XRD FTIR and XPS analyses, compared to the previously presented structure of chitosan-collagen gels before mineralization.
\end{abstract}

Keywords: chitosan, hydrogels, collagen, alkaline phosphatase.

\section{Introduction}

Chitosan, as a biomaterial, has unique properties (biocompatible, biodegradable) and is used to formed scaffolds for cell culture. They are produced as either dried forms or gels [1-7].

Hydrogels are especially interesting materials for scaffolds which are formed by increasing the temperature. They are characterized by the presence of water in the structure, increased flexibility (creating a structure similar to tissue) and the possibility of injecting the scaffold into diseased tissue [1].

In order to give the chitosan scaffolds osteoinductive properties, it is necessary to introduce calcium phosphate compounds into the structure, creating composite systems (i.e. where the so-called mineralization is conducted). The method of creating mineralized scaffolds relies mainly on introducing hydroxyapatite micro- or nanopellets into a chitosan salt, and then obtaining a 3D structure by phase separation or freezing and lyophilisation, or both processes one after the other.

For the ereation preparation of chitosan structures containing hydroxyapatite, the process of ion exchange is also used. Chitosan scaffolds are created at the same time as hydroxyapatite during the formation of the scaffold. In this case, reactions of phosphoric acid $\mathrm{H}_{3} \mathrm{PO}_{4}$ and calcium hydroxide $\mathrm{Ca}(\mathrm{OH})_{2}$ are applied. The phosphoric acid is added to a solution of chitosan salt (chitosan acetate) and introduced later into a suspension of calcium hydroxide. Hydroxyapatite may be also obtained in the structure by introducing calcium nitrate $\mathrm{Ca}\left(\mathrm{NO}_{3}\right)_{2}$ and ammonium (V), hydrogen phosphate $\left(\mathrm{NH}_{4}\right)_{2} \mathrm{HPO}_{4}$ or calcium nitrate $\mathrm{Ca}\left(\mathrm{NO}_{3}\right)_{2}$ and phosphoric acid $\mathrm{H}_{3} \mathrm{PO}_{4}$ or potassium dihydrogen phosphate $\mathrm{K}_{2} \mathrm{PO}_{4}$ into a solution of chitosan salt. In order to obtain a 
scaffold, a solution must be frozen, lyophilized and in some cases neutralized in $\mathrm{NaOH}$ and in ally washed [8-32].

Moreover the mussel-inspired chemistry is an important method for fabrication of different functional materials e.g hydrogels for different applications especially in the biomedical field. Biomineralization was adopted for the fabrication of hydroxyapatite termed polydopamineassisted hydroxyapatite formation,to integrate hydroxyapatites within scaffold materials [33-39].

In recent years, alkaline phosphatase has often been used in research into mineralization of scaffolds intended for osteoblast culture because ALP is the enzyme which participates during the bone mineralization processes.

A new trend in the process of mineralization of chitosan scaffolds is the introduction of ALP into the structure. During the incubation of the gel in a solution of calcium glycerophosphate (CaGP), ALP incorporated into the structure of the hydrogel induces the formation of the mineral calcium phosphate. The first research on introduction of ALP into the structure of chitosan gels formed under the influence of temperature were patented and presented in scientific papers [40-42].

Composite chitosan-collagen gels, including those formed at physiological body temperature are known in literature [43-45], whereas there is far less literature available on chitosan-collagen hydrogels containing ALP [46]. The structure of chitosan-collagen gels containing ALP after mineralization has not been published. Introducing collagen, the basic ingredient of bone tissue, into the structure of chitosan gels which are formed at physiological body temperature, aims to create so-called biomimetic structures (i.e. close to the composition of natural bone tissue).

The current research concerns the evaluation of the structure of composite chitosancollagen gels containing ALP after mineralization. The study references a previously published study on chitosan and chitosan-collagen gels containing ALP before mineralization by the same authors [46]. In this study, the following topics were investigated:

- The influence of collagen on the structural properties of thermosensitive chitosan gels before [46] and after mineralization

- The influence of ALP on structural properties of :

○ chitosan gels before [46] and after mineralization,

$\circ$ chitosan-collagen gels before [46] and after mineralization.

\section{Materials and methods}

Thermosensitive chitosan gels were prepared according to the method described by Chenite [47]. To prepare the hydrogels, shrimp chitosan (Sigma Aldrich Product No. 50494) of deacetylation degree SD $~ 79.5 \%$ and molecular weight $860 \mathrm{kD}$ were used. $0.4 \mathrm{~g}$ of chitosan powder was dissolved in $16 \mathrm{ml}$ of $0.1 \mathrm{M} \mathrm{HCl}$ (Sigma Aldrich). After preparing the chitosan solution in this way, it was left on a mechanical shaker for approximately $12 \mathrm{~h}$ to ensure complete dissolution. At the same time, $2 \mathrm{~g}$ sodium beta-glycerophosphate (Na- $\beta$-GP) (Sigma Aldrich Product No. 50020) was dissolved in $2 \mathrm{ml}$ of deionized water (18 $\mathrm{mS})$. The resulting chitosan salt solution was cooled to $4^{\circ} \mathrm{C}$. Na- $\beta$-GP solution was added and mixed to the chitosan solution (sol) drop by drop.

Thermosensitive chitosan gels containing ALP (Sigma Aldrich Product No. P7640) were created by adding $1 \mathrm{ml}$ of ALP dissolved in deionized water (at the concentrations: 2.5, 10, and $25 \mathrm{mg} / \mathrm{ml}$ ) to the $16 \mathrm{ml}$ chitosan chloride solution containing Na- $\beta$-GP. The final concentration of ALP in each hydrogel was $0.156 ; 0.625 ; 1.562 \mathrm{mg} / \mathrm{ml}$, respectively. 
Thermosensitive chitosan-collagen gels were created by adding 0.5 and $1 \mathrm{ml}$ of collagen (Sigma Aldrich Product No. C4243) to the $16 \mathrm{ml}$ chitosan chloride containing Na- $\beta$-GP.

Thermosensitive chitosan-collagen gels containing ALP were created by adding $1 \mathrm{ml}$ ALP dissolved in deionized water at concentrations of $2.5,10$, and $25 \mathrm{mg} / \mathrm{ml}$ into a chitosan solution containing Na- $\beta$-GP with collagen. The final concentration of ALP in each hydrogel was 0.156; $0.625 ; 1.562 \mathrm{mg} / \mathrm{ml}$ respectively.

All resulting solutions were incubated at $37^{\circ} \mathrm{C}$ for $24 \mathrm{~h}$ in order to complete their gelation.

The mineralization was conducted in static flow conditions. The gels containing ALP and gels with ALP and collagen were incubated in a solution of CaGP (Sigma Aldrich Product No. 50043) for $36 \mathrm{~h}$. $50 \mathrm{ml} 0.1 \mathrm{M} \mathrm{CaGP}$ solution was changed twice per day. After that, the samples were lyophilized.

The structural properties of the gels were determined by infrared spectroscopy with Fourier transformation (FTIR) using a Nicolet 6700 spectrometer from Thermo Nicolet equipped with a snap Photoacoustics MTEC model 300. Room temperature powder X-ray diffraction patterns (XRD) were collected using a PANalytical X'Pert Pro MPD diffractometer in the BraggBrentano reflection geometry. Copper $\mathrm{CuK}_{\alpha}$ radiation was used from a sealed tube $(40 \mathrm{kV}, 30$ $\mathrm{mA})$. Data was collected in the $2 \theta$ range $3-50^{\circ}$ with a step of $0.0167^{\circ}$ and an exposure per step of $20 \mathrm{~s}$. The samples were spun during data collection to minimize preferred orientation effects. Photoelectron spectra (XPS) were measured using the ESCALAB-210 spectrometer (VG Scientific). A non-chromatized source of x-ray radiation at a voltage of $15 \mathrm{kV}$ producing a radiation beam $\mathrm{Al} \mathrm{Ka}(1486.6 \mathrm{eV})$ at an intensity of $20 \mathrm{~mA}$ was used. The sample was measured after being pressed into a tablet, while maintaining a vacuum of $8^{*} 10^{-9}$ mbar in the analytical chamber of the spectrometer. A survey spectrum was made at pass energy in the hemispherical analyzer (pass energy, CAE) $=75 \mathrm{eV}$ and energy jump of $0.4 \mathrm{eV}$. High-resolution spectra were recorded at an analyser pass energy of $20 \mathrm{eV}$ with jump of $0.1 \mathrm{eV}$. For SEM imaging FEI QUANTA FEG 250 scanning electron microscope was used.

\section{Results and Discussion}

\subsection{Influence of collagen on the structural properties of thermosensitive chitosan gels}

The influence of collagen on the structural properties of thermosensitive chitosan gels before mineralisation are shown in Figure 1 (FTIR spectra), and after mineralization in Figure 2 (FTIR spectra) and Figure 3 (XRD dyfractogram). 


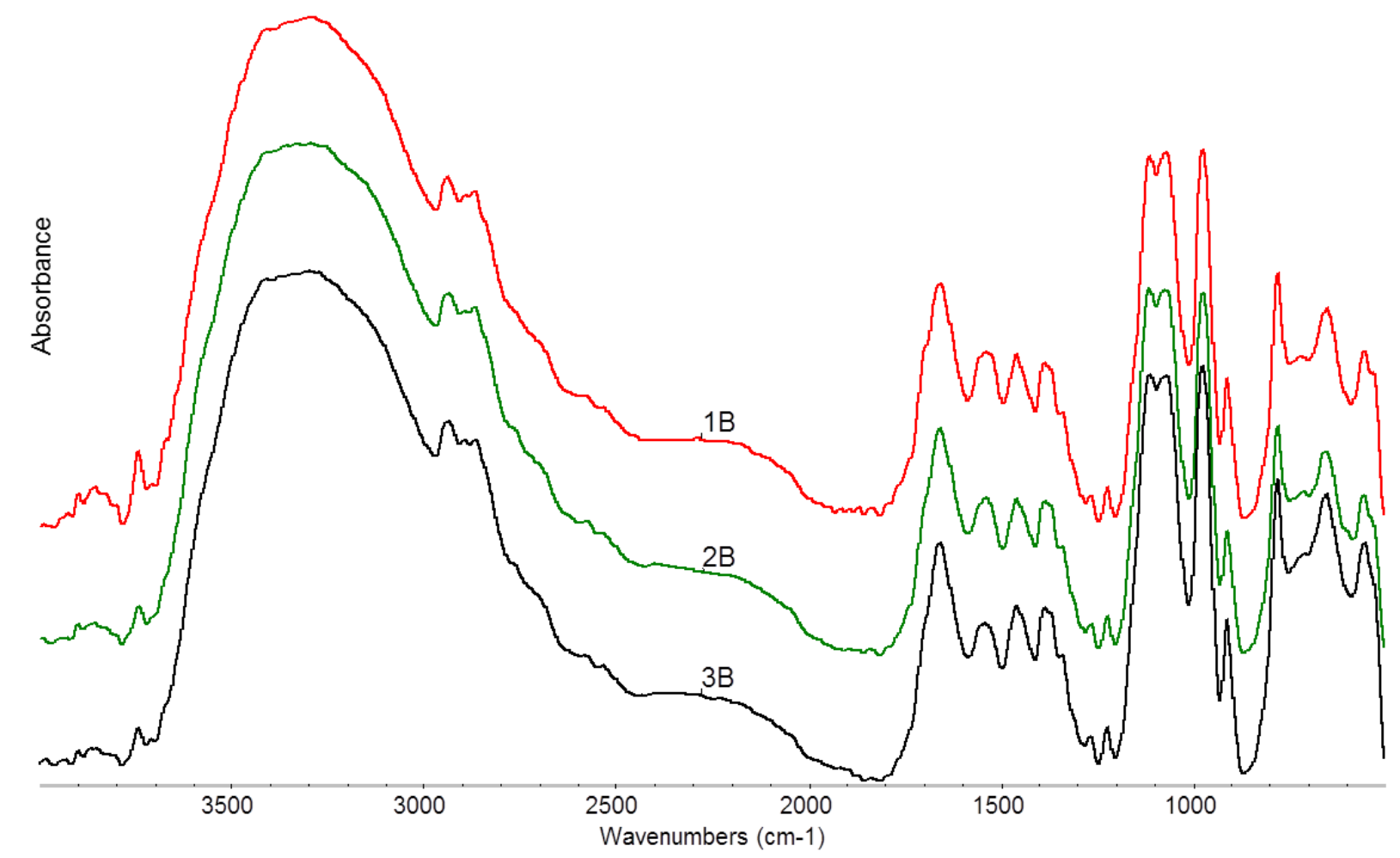

Figure 1. FTIR spectra for chitosan gels without collagen $(1 B)$ and containing collagen $0.5(2 B)$ and $1.0 \mathrm{ml}(3 \mathrm{~B})$ before mineralization [46] 


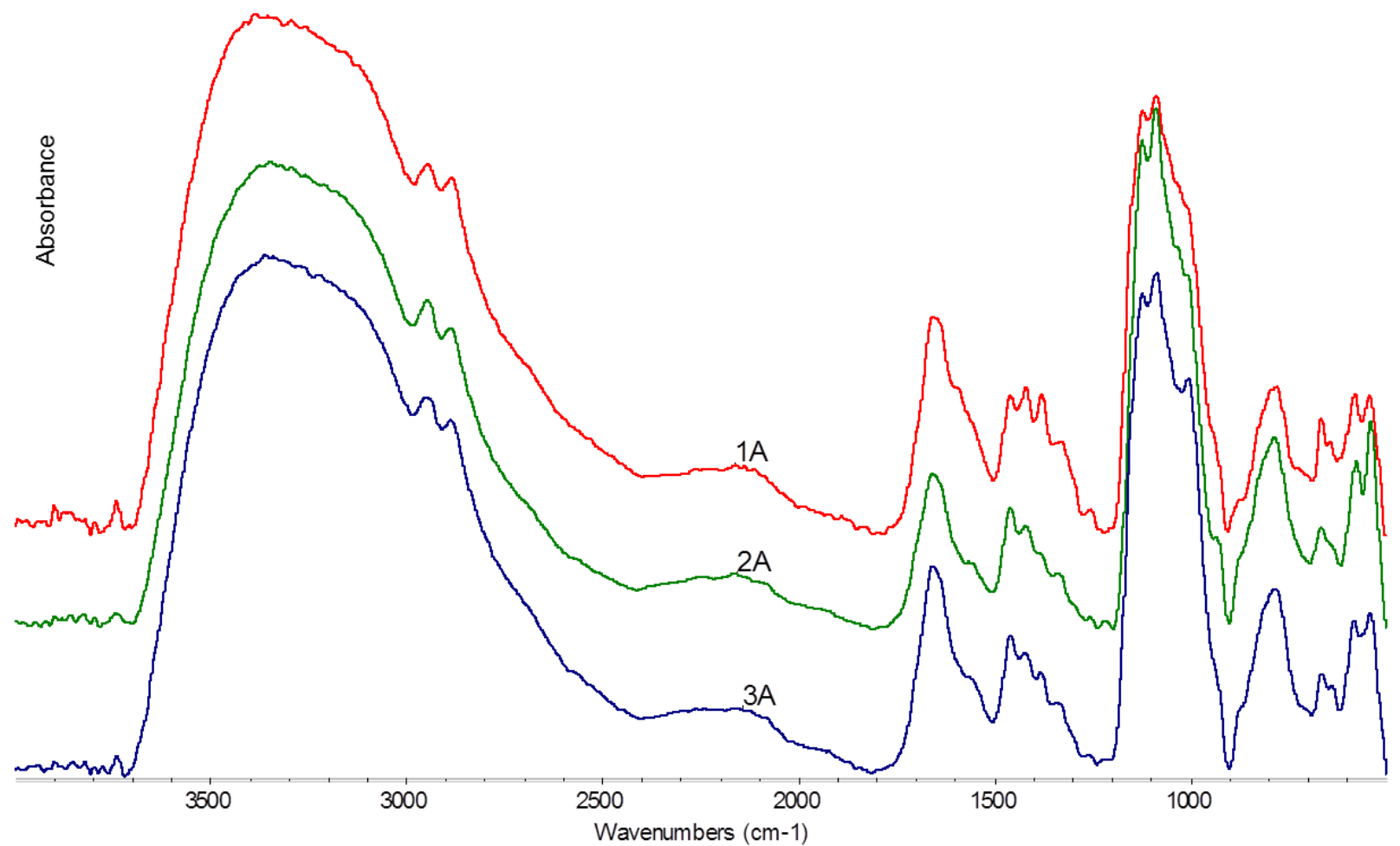

Figure 2. FTIR spectra for chitosan gels without collagen (1A) and containing collagen 0.5 (2A) and $1.0 \mathrm{ml}(3 \mathrm{~A})$ after mineralization

The presence of collagen in the chitosan gels does not cause any significant changes to the oscillations of chemical groups. After the introduction of collagen, we noticed a lower intensity of the arm of amide I band occurring at wavenumber $1700 \mathrm{~cm}^{-1}$ and the amide II band of secondary amides at wavenumber $1560 \mathrm{~cm}^{-1}$ [46].

Mineralization of chitosan and chitosan-collagen gels has a similar effect on the change of gel structure. Mineralization of chitosan gels shows a very strong influence of this process on the resonant frequencies of grouping vibrations in the whole spectral range, observed in We observe a deformation of oscillators $-\mathrm{O}-\mathrm{H}$ and N-H band at approximately ca. $3400 \mathrm{~cm}^{-1}$. Also, oscillation bands of $\mathrm{C}-\mathrm{H}$ groupings after the mineralization process increase the wavenumber of vibrations. This indicates significant changes in the conformation of chains and changes taking place in the supermolecular structure of the obtained gels.

In the spectra of chitosan and chitosan-collagen gels a band is visible next to the wavenumber $2450 \mathrm{~cm}^{-1}$. After mineralization, it moves towards the lower wavenumber $2150 \mathrm{~cm}^{-1}$.

The main changes are observed for wavenumbers corresponding to amide I band and amide II band of secondary amides, the saccharide structure and in the range of wave numbers connected with the presence of phospate ions.

In all cases the asymmetry of the band at $1660 \mathrm{~cm}^{-1}$ (arm at $1770 \mathrm{~cm}^{-1}$ ) and amide II band of secondary amides at $1540 \mathrm{~cm}^{-1}$ disappears, the intensity of bands at 1460, 1380, 1270 and $1225 \mathrm{~cm}^{-1}$ change, proportionally declining together with the reduction of the wavenumber; the band at $1420 \mathrm{~cm}^{-1}$ appears, which may also be the effect of moving the band at 1440 towards the lower wavenumbers. 
In the saccharide band in spectra of chitosan gels and chitosan-collagen gels is observed similar change. In the spectra of chitosan gels, bands at $1110 \mathrm{~cm}^{-1}$ and $1080 \mathrm{~cm}^{-1}$ are visible after the mineralization, the intensity of band at $1050 \mathrm{~cm}^{-1}$ increases in comparison with the intensity before the mineralization and the shape of the band changes and becomes visibly asymmetrical; this is probably connected with the disappearance of the band at $980 \mathrm{~cm}^{-1}$. Also the band at $910 \mathrm{~cm}^{-1}$ disappears, the band at $780 \mathrm{~cm}^{-1}$ becomes wider, the band at $650 \mathrm{~cm}^{-1}$ disappears and is visible with low intensity for wave number $670 \mathrm{~cm}^{-1}$ with an arm $650 \mathrm{~cm}^{-1}$; band $550 \mathrm{~cm}^{-1}$ after mineralization, it is divided into two bands: 580 and $520 \mathrm{~cm}^{-1}$.

In the spectra of chitosan-collagen gels the shape of the band at $1050 \mathrm{~cm}^{-1}$ is less asymmetrical; the band at $980 \mathrm{~cm}^{-1}$ is still clearly visible in comparison to the spectrum of chitosan gels, and the remaining changes are close to those in the spectrum of the chitosan gel.

Tensions in the polymer chains are visible through the increase of resonant frequencies of $\mathrm{C} O$ groups occurring both in the heterocyclic ring, and in the oxygen bridge at ca. $970 \mathrm{~cm}^{-1}$ for the gel. They all shift towards higher vibration energies after mineralization.

The mineralization of chitosan gels with the addition of collagen take a place without any major impact of the collagen concentrations on the observed changes in the molecular and supermolecular structure.

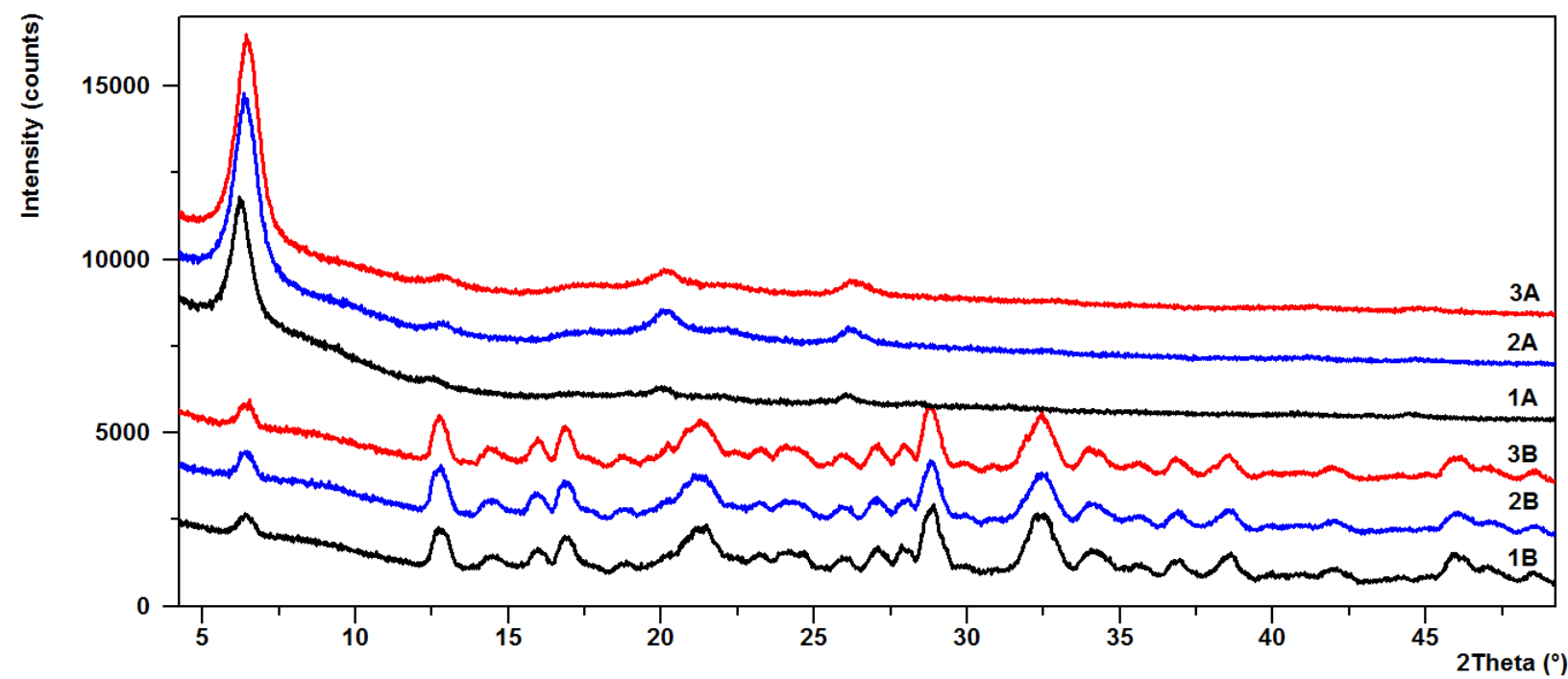

Figure 3. XRD diffraction patterns before $(B)$ and after $(A)$ mineralization for chitosan gel (1) and for chitosan gel containing collagen $0.5 \mathrm{ml}(2)$ and $1.0 \mathrm{ml}(3)$ respectively

XRD diffraction patterns before and after mineralization of chitosan and chitosan gels containing collagen $(0.5 \mathrm{ml}$ and $1.0 \mathrm{ml})$ samples are shown in Figure 3 . The crystalline structure of chitosan gels due to the presence of collagen does not change since the collagen-free and collagen-chitosan gels diffractograms are quite similar. They are characterized by a number of peaks that are particularly noticeable at an angle of $2 \theta$ about $6.4^{\circ}, 12.8^{\circ}, 16.9^{\circ}, 21.5^{\circ}, 28.9^{\circ}$ and $32.4^{\circ}$. The variation of collagen concentration does not affect the crystalline structure. After mineralization, we observed significant changes in the crystalline structure of study samples. The diffraction pattern of chitosan gel contains a strong, wide peak at an angle of $2 \theta$ about $6.5^{\circ}$ and several small broad peaks at an angle of $2 \theta$ about $12.8^{\circ}, 20,1^{\circ}$ and $26.1^{\circ}$. Similar changes we observe for chitosan gel containing collagen samples. This indicates the semi- 
crystalline nature of the study samples. In addition to the increase in collagen concentration, the intensity of these peaks decreases.

\subsection{Influence of ALP on the structural properties of chitosan and chitosan-collagen gels}

The FTIR spectra of chitosan and chitosan-collagen hydrogels containing $1 \mathrm{ml}$ of ALP in the concentration of $0,2.5,10$ and $25 \mathrm{mg} / \mathrm{ml}$ before mineralization are presented in Figure 4 and 5 and after mineralization in Figure 6 and 7 (changes with the addition of $0.5 \mathrm{ml}$ of collagen are the same). Figure 8 shows XRD diffraction patterns before and after mineralization.

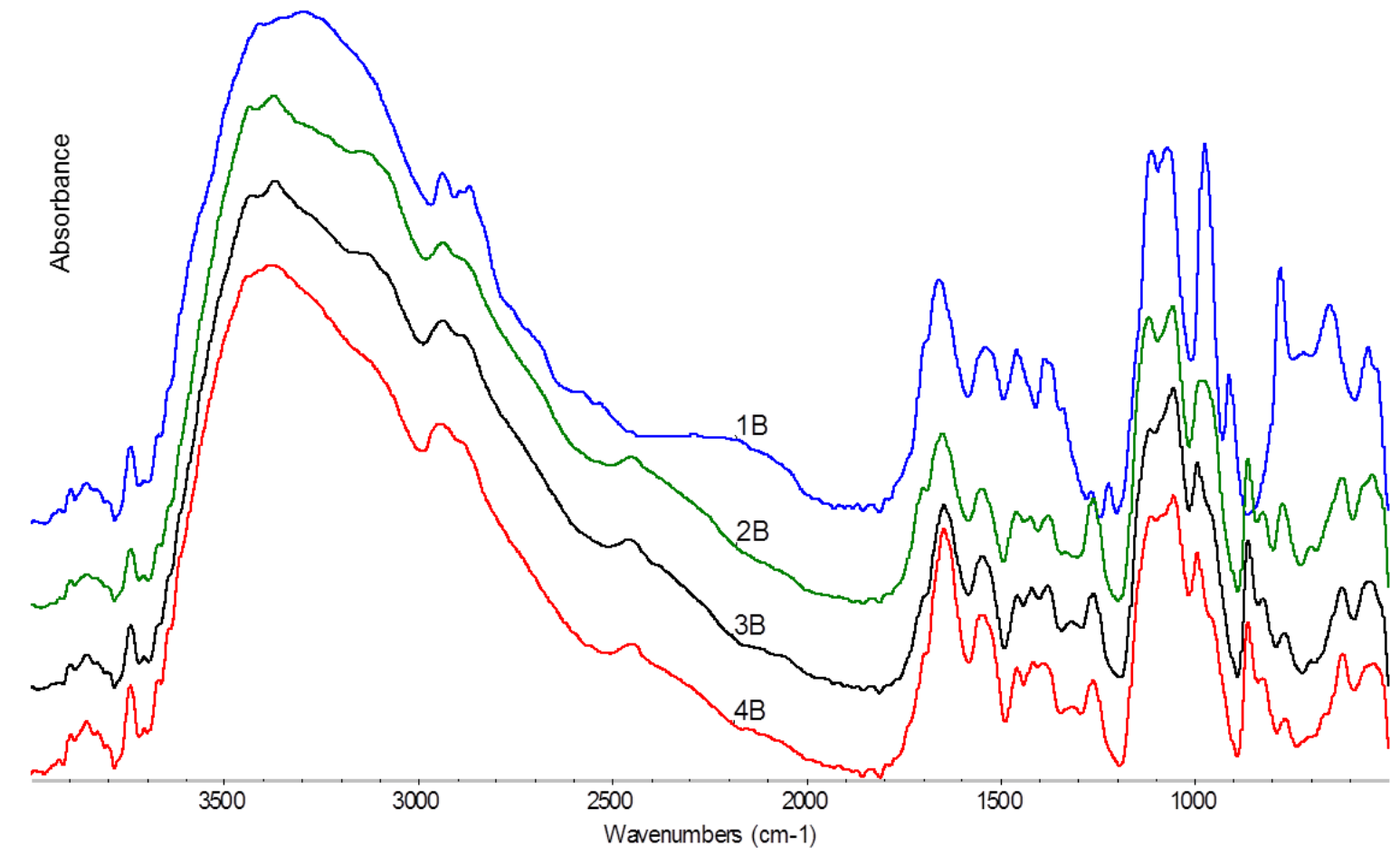

Figure 4. FTIR spectra for chitosan gel before mineralization (B) containing ALP $0 \mathrm{mg} / \mathrm{ml}(1 \mathrm{~B}), 2.5 \mathrm{mg} / \mathrm{ml}(2 \mathrm{~B}), 10 \mathrm{mg} / \mathrm{ml}(3 \mathrm{~B})$ and $25 \mathrm{mg} / \mathrm{ml}$ (4B) [46] 


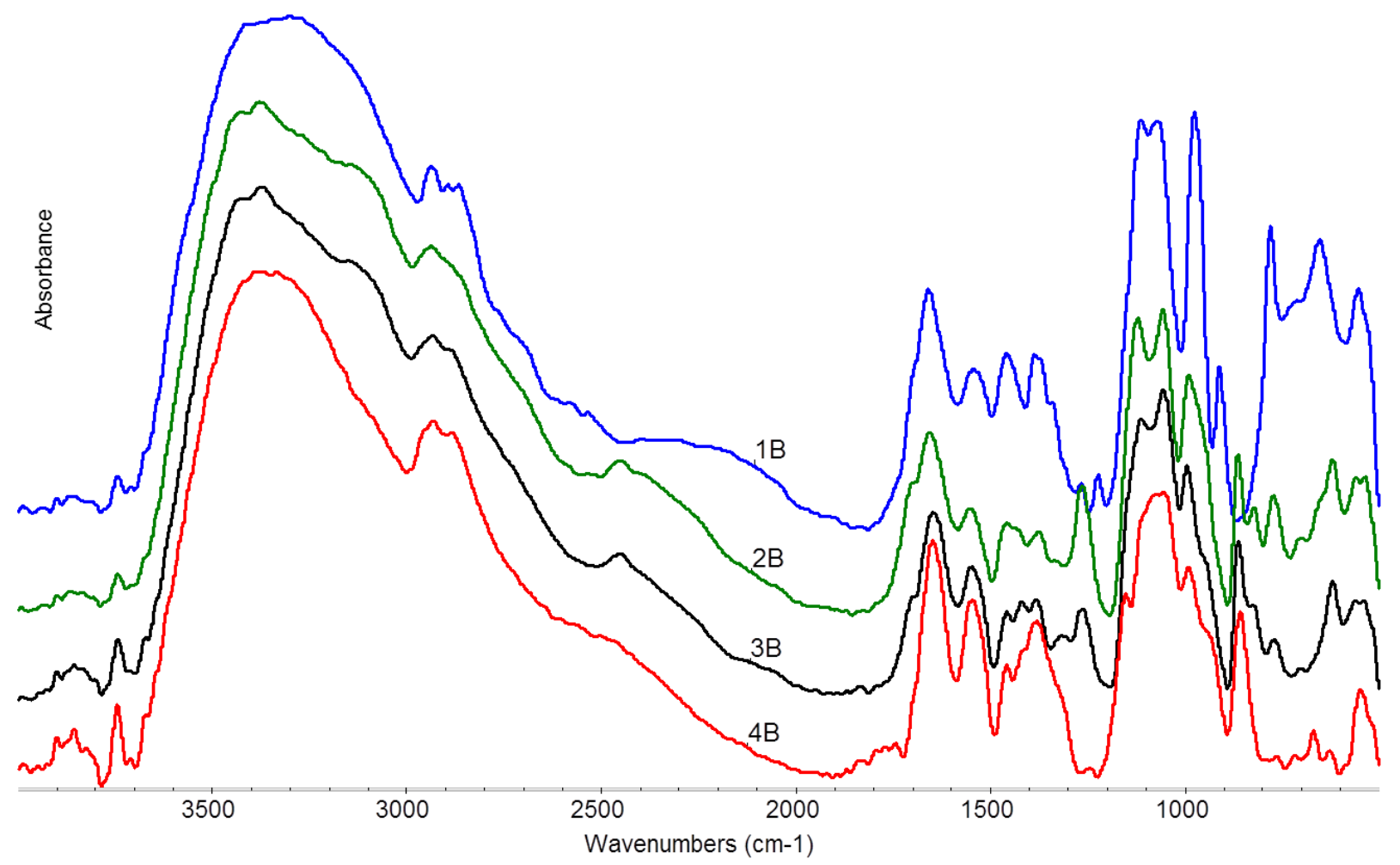

Figure 5. FTIR spectra for chitosan-collagen gel $1.0 \mathrm{ml}$ before mineralization $(B)$ - containing ALP $0 \mathrm{mg} / \mathrm{ml}$ (1B), $2.5 \mathrm{mg} / \mathrm{ml}$ (2B), $10 \mathrm{mg} / \mathrm{ml} \mathrm{(3B)} \mathrm{and} 25 \mathrm{mg} / \mathrm{ml}$ (4B) [46]

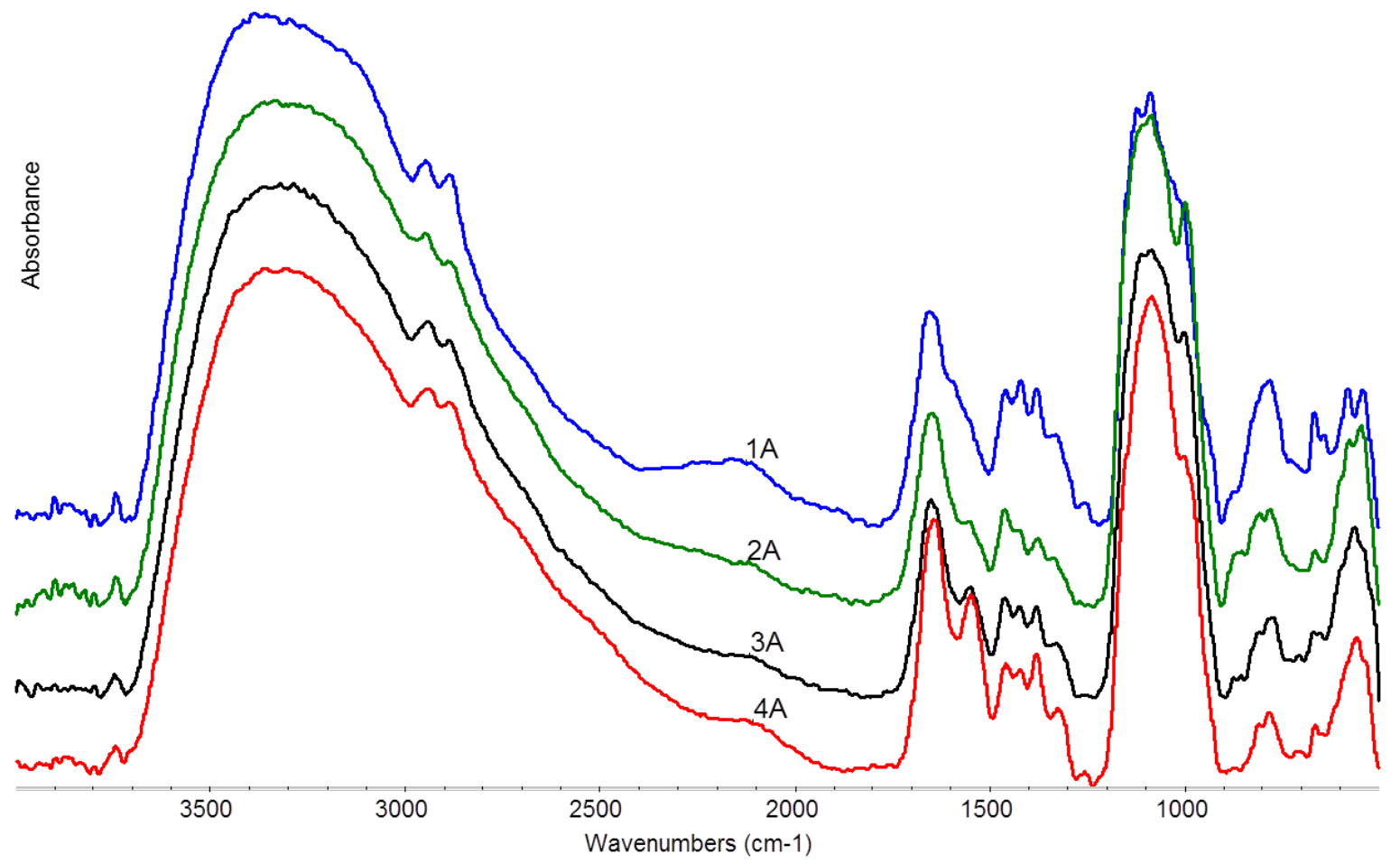


Figure 6. FTIR spectra for chitosan gel containing ALP after mineralization (A) - $0 \mathrm{mg} / \mathrm{ml}(1 \mathrm{~A})$, $2.5 \mathrm{mg} / \mathrm{ml}(2 \mathrm{~A}), 10 \mathrm{mg} / \mathrm{ml}(3 \mathrm{~A})$ and $25 \mathrm{mg} / \mathrm{ml}(4 \mathrm{~A})$

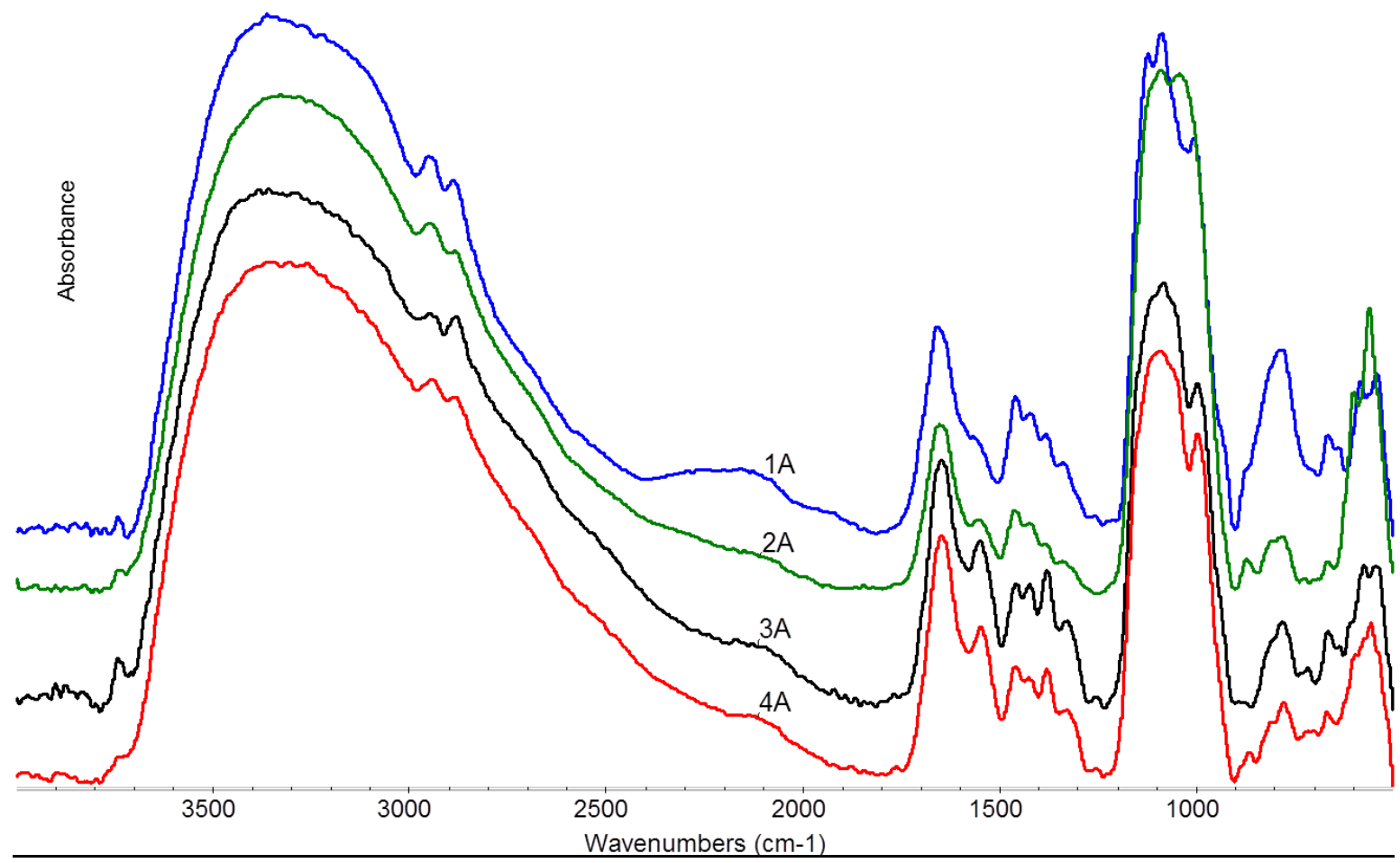

Figure 7. FTIR spectra for chitosan-collagen gel $1.0 \mathrm{ml}$ containing ALP after mineralization (A) - $0 \mathrm{mg} / \mathrm{ml}$ (1A), $2.5 \mathrm{mg} / \mathrm{ml}$ (2A), $10 \mathrm{mg} / \mathrm{ml}(3 \mathrm{~A})$ and $25 \mathrm{mg} / \mathrm{ml}(4 \mathrm{~A})$

The spectra before and after mineralization of chitosan hydrogels (Figure 4 and 6) and chitosan collagen- hydrogels containing ALP (Figure 5 and 7) indicate changes that can be observed in the wavenumber range $3000-3500 \mathrm{~cm}^{-1}$ and in the range of the saccharide structure, and in connection with the presence of phosphate ions in the range $1100-700 \mathrm{~cm}^{-1}$ [48-50].

Changes in the spectra in asymmetrical band corresponding to $\mathrm{O}-\mathrm{H}$ vibrations $\left(3600-3100 \mathrm{~cm}^{-1}\right)$ of chitosan and chitosan-collagen hydrogels before mineralization containing ALP and without ALP in asymmetrical band corresponding to $0-H_{\text {vibrations }}\left(36003100 \mathrm{~cm}^{-1}\right)$ are similar. The asymmetry is visible while moving towards lower wavenumbers, and is higher in the spectrum of hydrogels with ALP which indicates the presence of strong hydrogen-oxygen bonds and amine groups $\mathrm{N}-\mathrm{H}$ in the structure. As a result of introducing a low amount of ALP $2.5 ; 10 \mathrm{mg} / \mathrm{ml}$ in proportion to the weight of chitosan gel produced a specific effect of a significant change in the spectra was observed. In the range of oscillation of stretching groups $\mathrm{OH}$ and $\mathrm{N}-\mathrm{H}$ at circa $3400 \mathrm{~cm}^{-1}$ sharp peaks are formed. This phenomenon can be explained of $\mathrm{OH}$ and $\mathrm{N}-\mathrm{H}$ groups taking part in intermolecular bonds in various places of the polymer chain. This means that the supermolecular structure of chitosan is more organised.After the mineralization, no changes were observed in the spectra of chitosan and chitosan-collagen gels containing ALP in the range of the bands corresponding to $\mathrm{O}-\mathrm{H}$ vibrations, nor does the asymmetry connected with the presence of amine groups $\mathrm{N}-\mathrm{H}$. ehange

Stretching vibrations of aliphatic groups $-\mathrm{CH}_{2}$ and $-\mathrm{CH}_{3}$ of the spectra for chitosan and chitosan-collagen hydrogels at the wavenumbers $2800-2970 \mathrm{~cm}^{-1}$ are divided into three bands which peaks at wavenumbers $2870 \mathrm{~cm}^{-1}, 2890 \mathrm{~cm}^{-1}$ and $2940 \mathrm{~cm}^{-1}$. For hydrogels containing 
ALP, the two maximum bands can be observed at wavenumbers $2940 \mathrm{~cm}^{-1}$ and $2890 \mathrm{~cm}^{-1}$. After mineralization in all cases, the spectra are observed two bands at $2890 \mathrm{~cm}^{-1}$ and $2940 \mathrm{~cm}^{-1}$. In the wavenumber stretching vibrations of aliphatic groups $\left(\mathrm{CH}_{2}\right.$ and $\left.\mathrm{CH}_{3}\right),\left(28002970 \mathrm{~cm}^{-1}\right)$ - the spectra of chitosan and chitosan-collagen hydrogels are divided into three bands which peak at wavenumbers $2870 \mathrm{~cm}^{-1}, 2890 \mathrm{~cm}^{-1}$ and $2940 \mathrm{~cm}^{-1}$. For hydrogels containing ALP, the wavenumbers at $2870 \mathrm{~cm}^{-1}$ disappears, the two maximum bands can be observed at wavenumbers $2940 \mathrm{~cm}^{-1}$ and $2890 \mathrm{~cm}^{-1}$. After mineralization in all cases, the wavenumbers at $2870 \mathrm{~cm}^{-1}$ disappears, the spectra are observed two bands at $2890 \mathrm{~cm}^{-1}$ and $2940 \mathrm{~cm}^{-1}$.

In spectra of chitosan-collagen hydrogels before mineralization a very wide band was also observed at $25002050 \mathrm{~cm}^{-1}$, but after introducing ALP this band disappears (Figure 5). with decreases together with an increase in ALP concentration in the gel. In the spectra of the hydrogels after mineralization the band appears at wavenumber $2150 \mathrm{~cm}^{-1}$ and with an increase of ALP concentration it moves towards lower wavenumbers and disappears.

In spectra before mineralization of chitosan and chitosan hydrogels containing ALP (Figure 5), changes in their structure can also be observed in this wavenumber range, mainly in the range of amide I band and amide II band of secondary amides. In the spectra of chitosan and chitosan-collagen gels before mineralization bands at wavenumbers $1660 \mathrm{~cm}^{-1}$ were observed with a slight asymmetry towards higher wave numbers $1700 \mathrm{~cm}^{-1}$ and a number of bands for wavenumbers $1540,1460,1380,1340,1270,1220 \mathrm{~cm}^{-1}$. Spectra-in the presence of ALP in the structure of for chitosan and chitosan collagen gels with ALP it varies depending on the concentration of ALP. The presence of ALP in the structure for low ALP concentrations $2.5 \mathrm{mg} / \mathrm{ml}$ makes the band at $1700 \mathrm{~cm}^{-1}$ more visible in the spectra; however for the concentration of ALP $25 \mathrm{mg} / \mathrm{ml}$ the band disappears. The intensity of band $1540 \mathrm{~cm}^{-1}$ increases for the largest addition of ALP, i.e. $25 \mathrm{mg} / \mathrm{ml}$. In the range of low ALP concentrations a very intensive band is present at $1260 \mathrm{~cm}^{-1}$; however the intensity decreases together with the increase of ALP concentration (at high ALP and collagen concentrations the band disappears). After mineralization the amide I band at $1660 \mathrm{~cm}^{-1}$ remains unchanged, both in the spectra of chitosan gels and chitosan-collagen gels, while the amide II band of secondary amides occurring at wave number $1550 \mathrm{~cm}^{-1}$ becomes more visible as ALP concentration increases.

Before mineralization in spectra of chitosan and chitosan-collagen with and without ALP (Figure 5) major changes in the band in the saccharide structure at the wavenumber range $1200-900 \mathrm{~cm}^{-1}$ can be observed. In spectra of chitosan and chitosan-collagen without ALP at wave numbers 1110, 1070 (stretching vibrations P-O-C), $975\left(-\mathrm{PO}_{4}{ }^{3-}\right), 910\left(-\mathrm{HPO}_{4}{ }^{2-}\right), 780,650$ and $554 \mathrm{~cm}^{-1}$ were observed. These are bands deriving from both the saccharide structure and resulting from the presence of Na- $\beta-\mathrm{GP}$.

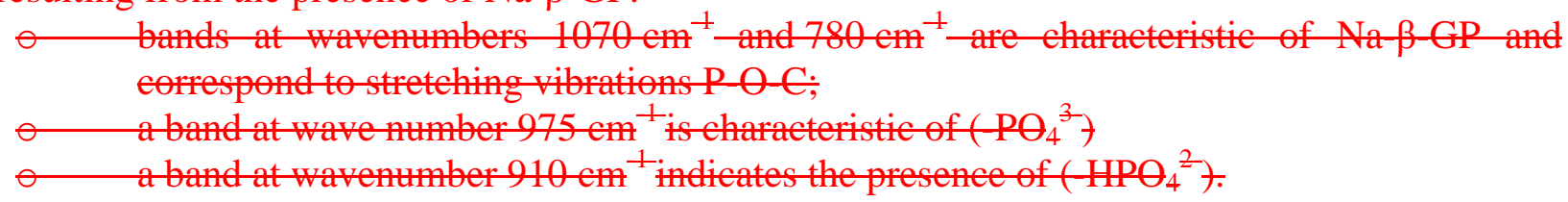

Before mineralization in the range of For low ALP concentrations in chitosan-collagen (Figure 5) gels spectra, bands at $1115 \mathrm{~cm}^{-1}$ and $1055 \mathrm{~cm}^{-1}$ are separated and at high ALP concentrations they combine; at high ALP concentrations a new band for wavenumber $1150 \mathrm{~cm}^{-1}$ appears; the intensity of the band at wavenumber $975 \mathrm{~cm}^{-1}$ definitely decreases, and together with the increase of ALP concentration it becomes more asymmetrical. A band appears at wavenumber $860 \mathrm{~cm}^{-1}$ with an arm at $820 \mathrm{~cm}^{-1}$, the arm disappears at high ALP concentrations. The band at wavenumber $910 \mathrm{~cm}^{-1}$ disappears, the band at wavenumber $780 \mathrm{~cm}^{-1}$ decreases 
intensity, and the band at wavenumber $650 \mathrm{~cm}^{-1}$ moves towards lower wavenumber $610 \mathrm{~cm}^{-1}$.After the introduction of ALP in chitosan hydrogels, the spectrum in this wavenumber range changes: the intensity of the band at $1110 \mathrm{~cm}^{-1}$ decreases, the band at $1070 \mathrm{~cm}^{-1}$ shifts towards the lower wavenumber $1055 \mathrm{~cm}^{-1}$, the intensity of band at wavenumber $975 \mathrm{~cm}^{-1}$ decreases and, for the large additions of ALP, moves towards the higher wavenumber $994 \mathrm{~cm}^{-1}$; the bands at wavenumbers 910 and $780 \mathrm{~cm}^{-1}$ decrease, and the band at wavenumber $650 \mathrm{~cm}^{-1}$ moves towards the lower wavenumber $610 \mathrm{~cm}^{-1}$. Also, after adding ALP, bands appear at wavenumbers $860 \mathrm{~cm}^{-1}$ and $820 \mathrm{~cm}^{-1}$.

After mineralization in the spectra for chitosan hydrogels with ALP (Figure 6) in the range of the saccharide band, the bands at $1110 \mathrm{~cm}^{-1}, 1080 \mathrm{~cm}^{-1}$ and $1050 \mathrm{~cm}^{-1}$ combine, a band is formed at $980 \mathrm{~cm}^{-1}$, the wide asymmetrical band at wavenumber $800 \mathrm{~cm}^{-1}$ divides into two bands at $820 \mathrm{~cm}^{-1}$ and $780 \mathrm{~cm}^{-1}$, the band at $660 \mathrm{~cm}^{-1}$ loses intensity and its arm at $650 \mathrm{~cm}^{-1}$ disappears. The bands at $590 \mathrm{~cm}^{-1}$ and $540 \mathrm{~cm}^{-1}$ combine. After mineralization, in the spectra of chitosan-collagen gels a with ALP (Figure 7) the range of the saccharide band, also all bands $1110 \mathrm{~cm}^{-1}, 1080 \mathrm{~cm}^{-1}$ and $1050 \mathrm{~cm}^{-1}$ combine. In gels of higher concentrations of collagen, the band at $980 \mathrm{~cm}^{-1}$ becomes more visible (than in the gels without collagen), similarly to mineralized chitosan gels, a band at $870 \mathrm{~cm}^{-1}$ appears, a wide asymmetrical band at wavenumber $780 \mathrm{~cm}^{-1}$ decreases its intensity after the addition of ALP and divides into two bands at $820 \mathrm{~cm}^{-1}$ and $780 \mathrm{~cm}^{-1}$, the intensity of band $660 \mathrm{~cm}^{-1}$ decreases and its arm $650 \mathrm{~cm}^{-1}$ disappears; bands $590 \mathrm{~cm}^{-1}$ and $540 \mathrm{~cm}^{-1}$ combine.

The FTIR spectra of chitosan-collagen gel samples with and without the addition of ALP show a strong influence of ALP addition on the conformation and the intermolecular form of gels. This is probably triggered by blocking of the polar groups by ALP. This influence is, in turn, stimulated by collagen. In the spectra deformation oscillations of groups containing $\mathrm{C}-\mathrm{O}$ and $\mathrm{C}-\mathrm{O}-\mathrm{C}$ bonds can be observed in a wide range of wavenumbers depending on the presence of a given group. The spectra of chitosan gel after addition of ALP shows very significant changes in the supermolecular construction, regardless of the amount of ALP added. Even the smallest amount of ALP has a strong impact on the conformation of chitosan, and, as a result, its ability to organise molecules during binding. This can be explained by a direct and strong impact of -OH and $\mathrm{N}-\mathrm{H}$, which, at the same time, enables an unconstrained migration of molecules during binding. The result of this phenomenon is, for instance, a band moving from $910 \mathrm{~cm}^{-1}$ to $864 \mathrm{~cm}^{-1}$. Increasing the amount of ALP has no further impact on the changes in conformation, probably due to earlier saturation of groups forming intermolecular bonds.

After mineralization in the spectra for chitosan hydrogels with ALP in the range of the saccharide band, the bands at $1110 \mathrm{~cm}^{4}, 1080 \mathrm{~cm}^{-1}$ and $1050 \mathrm{~cm}^{-}$-combine, a band is formed at $980 \mathrm{~cm}^{4}$, the wide asymmetrical band at wavenumber $800 \mathrm{~cm}^{4}$-divides into two bands at $820 \mathrm{~cm}^{4}$ and $780 \mathrm{~cm}^{4}$, the band at $660 \mathrm{~cm}^{+}$loses intensity and its arm at $650 \mathrm{~cm}^{-1}$-disappears. The bands at $590 \mathrm{~cm}^{-1}$ and $540 \mathrm{~cm}^{-1}$ combine.

After mineralization, in the spectra of chitosan collagen gels a with ALP the range of the saccharide band, also all bands $1110 \mathrm{~cm}^{-1}, 1080 \mathrm{~cm}^{-1}$ and $1050 \mathrm{~cm}^{-1}$ eombine. In gels of higher concentrations of collagen, the band at $980 \mathrm{~cm}^{-1}$ becomes more visible (than in gels without collagen), similarly to mineralized chitosan gels, a band at $870 \mathrm{~cm}^{-1}$ appears, a wide asymmetricat band at wavenumber $780 \mathrm{~cm}^{-1}$-decreases its intensity after the addition of $\Lambda L P$ and divides int two bands at $820 \mathrm{~cm}^{-1}$ and $780 \mathrm{~cm}^{-1}$, the intensity of band $660 \mathrm{~cm}^{-1}$-decreases and its arm $650 \mathrm{~cm}^{-1}$-disappears; bands $590 \mathrm{~cm}^{-1}$ and $540 \mathrm{~cm}^{-1}$-combine. 


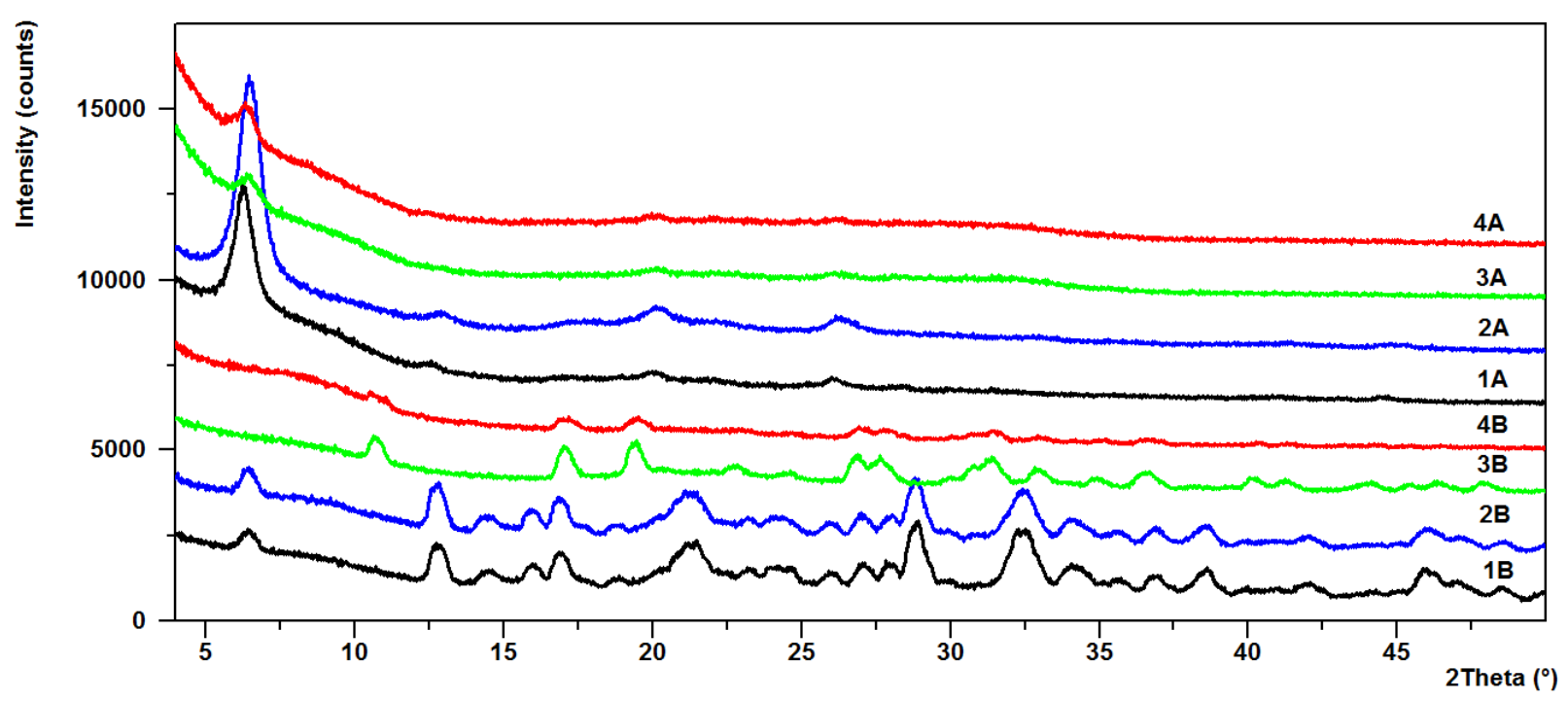

Figure 8. XRD diffraction patterns before $(B)$ and after $(A)$ mineralization for chitosan gel (1); chitosan-collagen $1.0 \mathrm{ml}$ gel (2); chitosan-ALP gel (3) and chitosan-collagen-ALP (4) gel respectively

Significant changes in the crystalline structure are observed after the introduction of ALP into the chitosan gel (Figure 8). Before mineralization, there are several maxima observed at an angle of $2 \theta$ about $10.7^{\circ}, 17.0^{\circ}, 19.4^{\circ}, 26.9^{\circ}, 27.6^{\circ}, 31.4^{\circ}, 32.9^{\circ}$ and $36.6^{\circ}$. In chitosan-collagenALP gels these peaks are also present but of less intensity. After mineralization, the structure of both chitosan and chitosan-collagen-ALP containing gels becomes more amorphous, with only a wide peak at an angle of $2 \theta$ of about $6.4^{\circ}$

A change of the structure of chitosan-collagen hydrogels before and after the mineralization process was determined on the basis of FTIR spectra and confirmed by XPS analysis. The XPS results are presented in Table 1, Table 2 and Table 3.

Table 1. Analysis of XPS spectra

\begin{tabular}{|c|c|c|c|c|c|c|c|c|c|c|c|}
\hline & & Chitosa & hydrogel & $\begin{array}{r}\text { Chitosa } \\
+\mathrm{c}\end{array}$ & $\begin{array}{l}\text { ydrogel } \\
\text { gen }\end{array}$ & $\begin{array}{l}\text { Chitosa } \\
+ \text { collag }\end{array}$ & $\begin{array}{l}\text { ydrogel } \\
+ \text { ALP }\end{array}$ & $\begin{array}{r}\text { Chitosa } \\
+\end{array}$ & $\begin{array}{l}\text { ydrogel } \\
\mathbf{P}\end{array}$ & $\begin{array}{l}\text { Chitosa } \\
+ \text { collag }\end{array}$ & $\begin{array}{l}\text { ydrogel } \\
+ \text { ALP }\end{array}$ \\
\hline & & & & Before $n$ & eralizatio & & & & After min & alization & \\
\hline & & 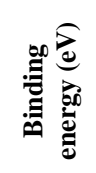 & 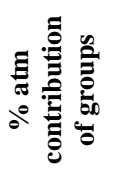 & 包 & 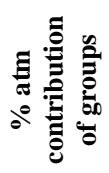 & 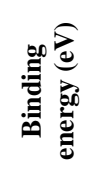 & 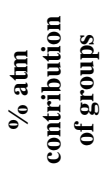 & 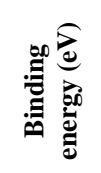 & 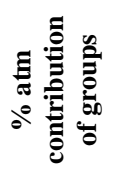 & 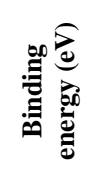 & 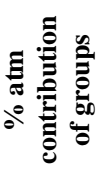 \\
\hline $\mathrm{Na}$ & & 1070.8 & $\begin{array}{l}16.5 \\
16.5\end{array}$ & 1070.9 & $\begin{array}{l}17.7 \\
17.7\end{array}$ & 1071.00 & $\begin{array}{l}8.89 \\
8.89\end{array}$ & & & & \\
\hline $\mathrm{O} 1 \mathrm{~s}$ & $\mathrm{NH}(\mathrm{C}=\mathrm{O})-\mathrm{C}$ & 530.16 & 14.1 & 530.46 & 20.4 & 530.87 & 14.35 & 531.55 & 7.95 & 530.72 & 26.11 \\
\hline $\mathrm{O} 1 \mathrm{~s}$ & $\begin{array}{l}\mathrm{C}-\mathrm{OH} \\
\mathrm{C}-\mathrm{O}-\mathrm{C}\end{array}$ & 531.91 & 19.3 & 532.28 & 19.8 & 532.48 & 18.17 & 533.21 & 30.60 & 532.58 & 21.32 \\
\hline $\mathrm{O} 1 \mathrm{~s}$ & $\beta(1 \rightarrow 4)$ & 535.65 & $\begin{array}{l}9.6 \\
43\end{array}$ & 535.61 & $\begin{array}{c}6.9 \\
47.1\end{array}$ & 535.98 & $\begin{array}{c}4.43 \\
36.95\end{array}$ & & 38.55 & & 47.43 \\
\hline $\mathrm{N} 1 \mathrm{~s}$ & C-NH ${ }_{2}$ & 399.18 & 0.9 & 401.65 & 1.2 & 399.58 & 3.21 & 399.67 & 2.94 & 399.21 & 2.61 \\
\hline
\end{tabular}




\begin{tabular}{|c|c|c|c|c|c|c|c|c|c|c|c|}
\hline $\mathrm{N} 1 \mathrm{~s}$ & $\mathrm{O}=\mathrm{C}-\mathrm{N}$ & & & 399.22 & \multicolumn{2}{|l|}{0.3} & & \multirow{2}{*}{$\frac{400.64}{402.31}$} & \multirow{2}{*}{$\begin{array}{l}2.52 \\
0.76\end{array}$} & \multirow[t]{2}{*}{401.24} & \multirow[t]{2}{*}{0.56} \\
\hline \multirow[t]{2}{*}{$\mathrm{N} 1 \mathrm{~s}$} & \multirow[t]{2}{*}{${\mathrm{C}-\mathrm{NH}_{3}{ }^{+}}^{+}$} & & & & & & & & & & \\
\hline & & & 0.9 & & 1.5 & & 3.21 & & 6.22 & & 3.17 \\
\hline $\mathrm{Ca} 2 \mathrm{p} 3$ & & & & 346.98 & 0.1 & & & 347.65 & 1.13 & 346.90 & 5.56 \\
\hline $\mathrm{Ca} 2 \mathrm{p} 1$ & & & & 350.48 & 0.0 & & & 351.21 & 0.57 & 350.44 & 2.78 \\
\hline & & & & & 0.1 & & & & 1.70 & & 8.34 \\
\hline $\mathrm{C} 1 \mathrm{~s}$ & C-C $\quad$ C-H & 284.60 & 10.0 & 284.60 & 8.8 & 284.60 & 17.71 & 284.60 & 7.62 & 284.60 & 9.31 \\
\hline $\mathrm{C} 1 \mathrm{~s}$ & $\mathrm{C}-\mathrm{NH}_{2}$ & 285.97 & 9.0 & 286.06 & 12.5 & 285.83 & 17.22 & 285.89 & 20.94 & 286.32 & 9.81 \\
\hline $\mathrm{C} 1 \mathrm{~s}$ & $\begin{array}{l}\mathrm{C}-\mathrm{OH} \\
\mathrm{C}-\mathrm{O}-\mathrm{C}\end{array}$ & & 6.9 & 287.62 & 3.3 & 286.55 & 5.93 & 286.78 & 12.75 & 287.62 & 4.56 \\
\hline $\mathrm{C} 1 \mathrm{~s}$ & $\begin{array}{c}\mathrm{NH}(\mathrm{C}=\mathrm{O}) \\
\mathrm{O}-\mathrm{C}-\mathrm{O}\end{array}$ & 288.12 & & 289.03 & 0.8 & 287.70 & 4.25 & 287.69 & 6.70 & 285.82 & 7.97 \\
\hline $\mathrm{C} 1 \mathrm{~s}$ & $(\mathrm{C}=\mathrm{O})-\mathrm{O}$ & & 49.48 & & 25.3 & & 45.11 & 288.83 & $\begin{array}{c}2.52 \\
50.52\end{array}$ & 288.72 & $\begin{array}{c}1.23 \\
32.88\end{array}$ \\
\hline $\mathrm{Cl} 2 \mathrm{p} 3$ & & 198.49 & 3.8 & 198.35 & 0.5 & 197.38 & 0.24 & & & & \\
\hline $\mathrm{Cl} 2 \mathrm{p} 1$ & & 200.09 & 1.9 & 199.95 & 0.2 & 198.98 & 0.12 & & & & \\
\hline $\mathrm{Cl} 2 \mathrm{p} 3$ & & & & & & 199.24 & 0.69 & & & & \\
\hline $\mathrm{Cl} 2 \mathrm{p} 1$ & & & & & & 200.84 & 0.34 & & & & \\
\hline & & & 5.8 & & 0.7 & & 1.39 & & & & \\
\hline P 2p3 & & 132.56 & 4.7 & 132.71 & 5.1 & 132.97 & 2.97 & & 2.00 & 132.76 & 5.46 \\
\hline P 2p1 & & 133.40 & 2.4 & 133.57 & 2.5 & 133.81 & 1.48 & & 1.01 & 133.60 & 2.73 \\
\hline & & & 7.1 & & 7.6 & & 4.45 & & 3.01 & & 8.19 \\
\hline $\mathrm{Ca} / \mathbf{P}$ & & & & & & & & & 0.56 & & 1.018 \\
\hline
\end{tabular}

Table 2. Distribution of XPS spectra for gels before mineralization

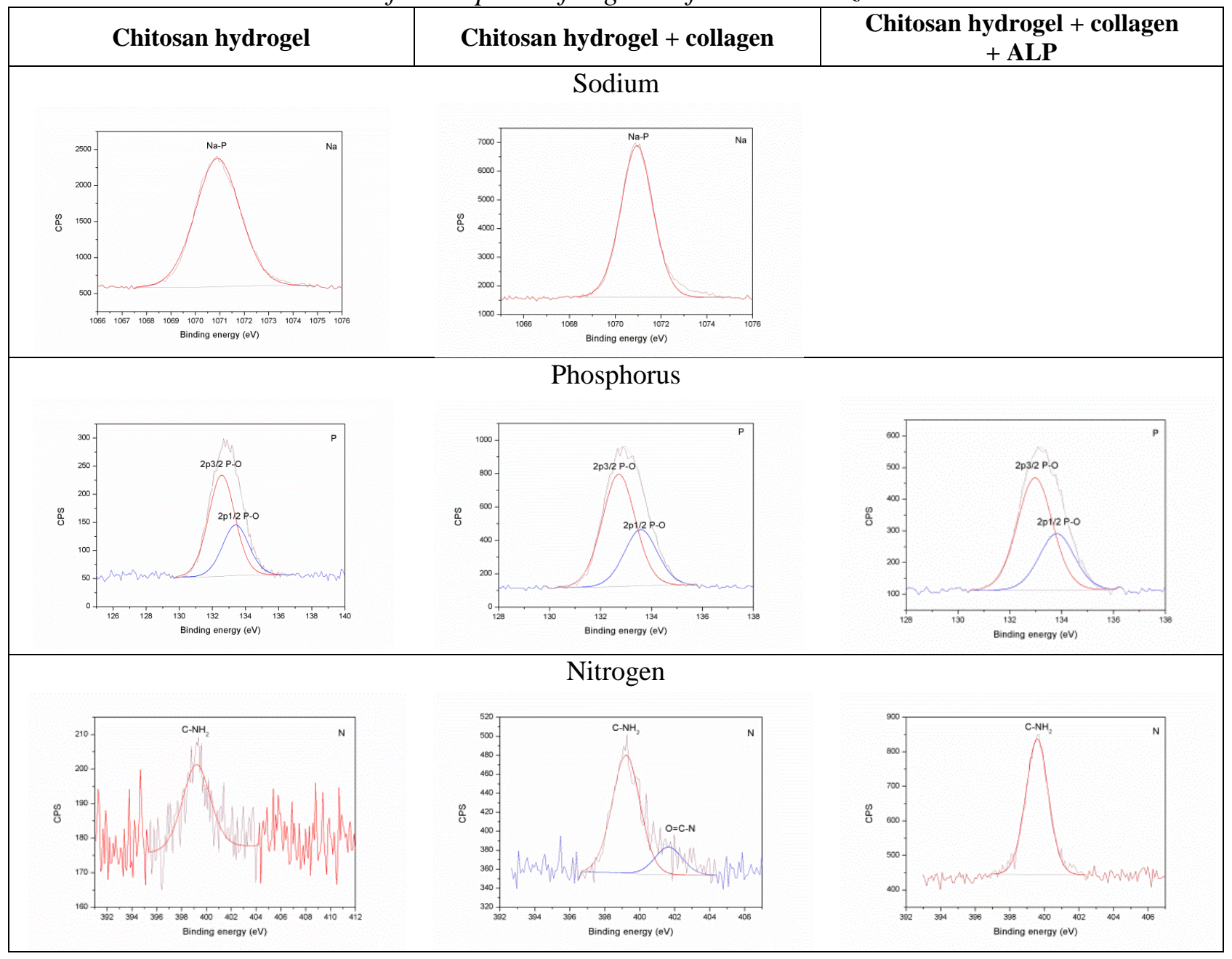




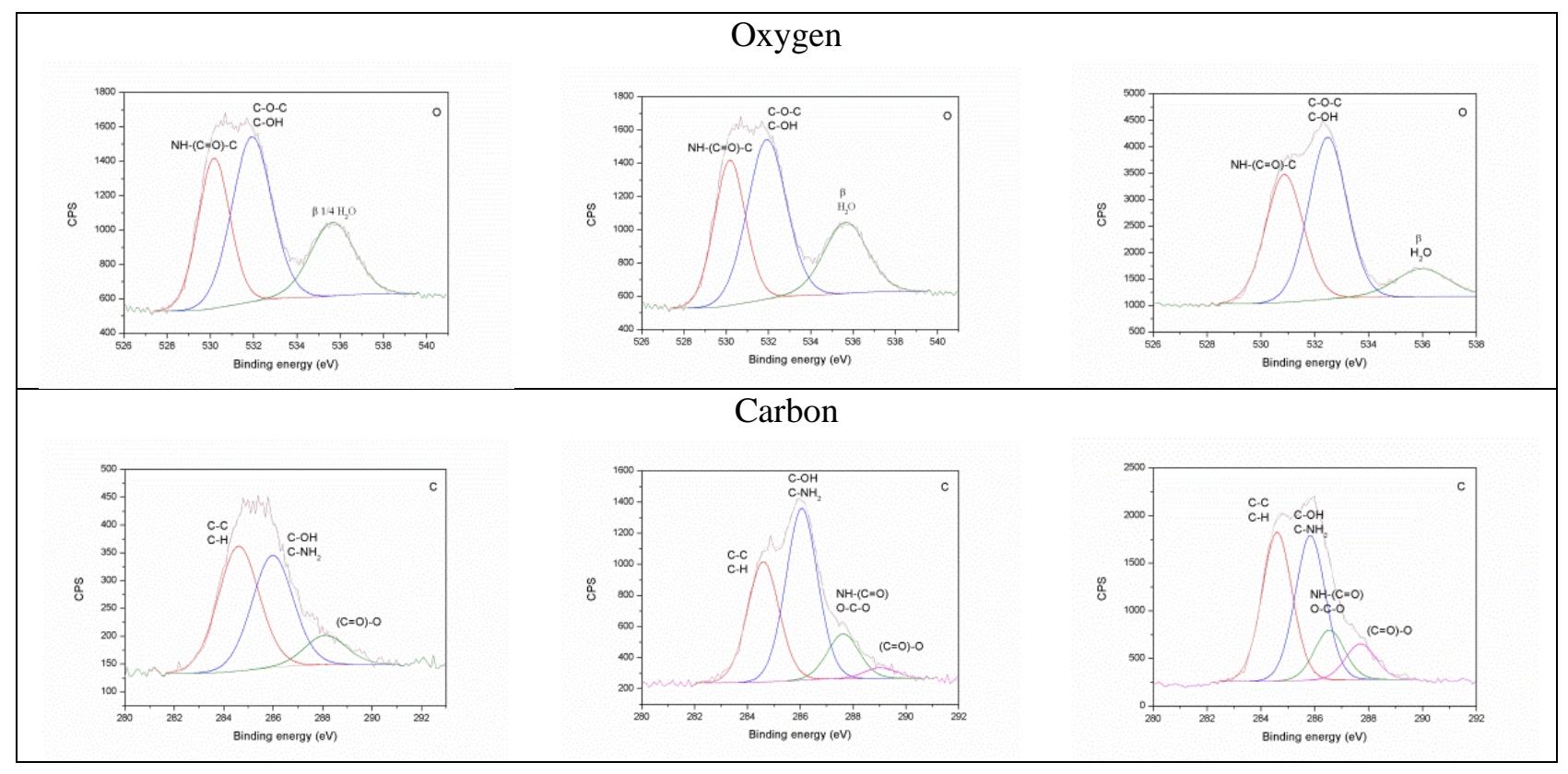

Table 3. Distribution of XPS spectra for gels after mineralization

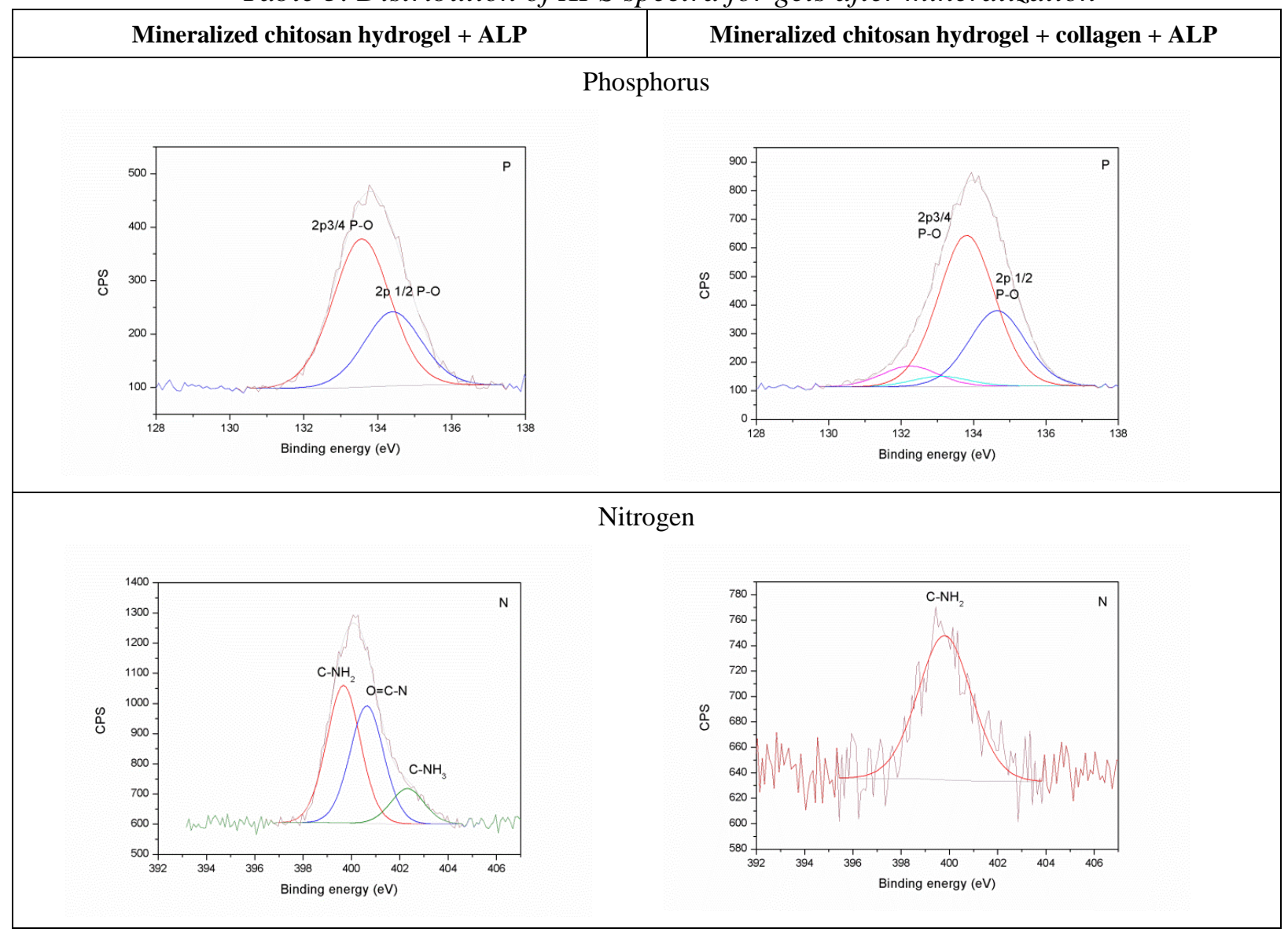




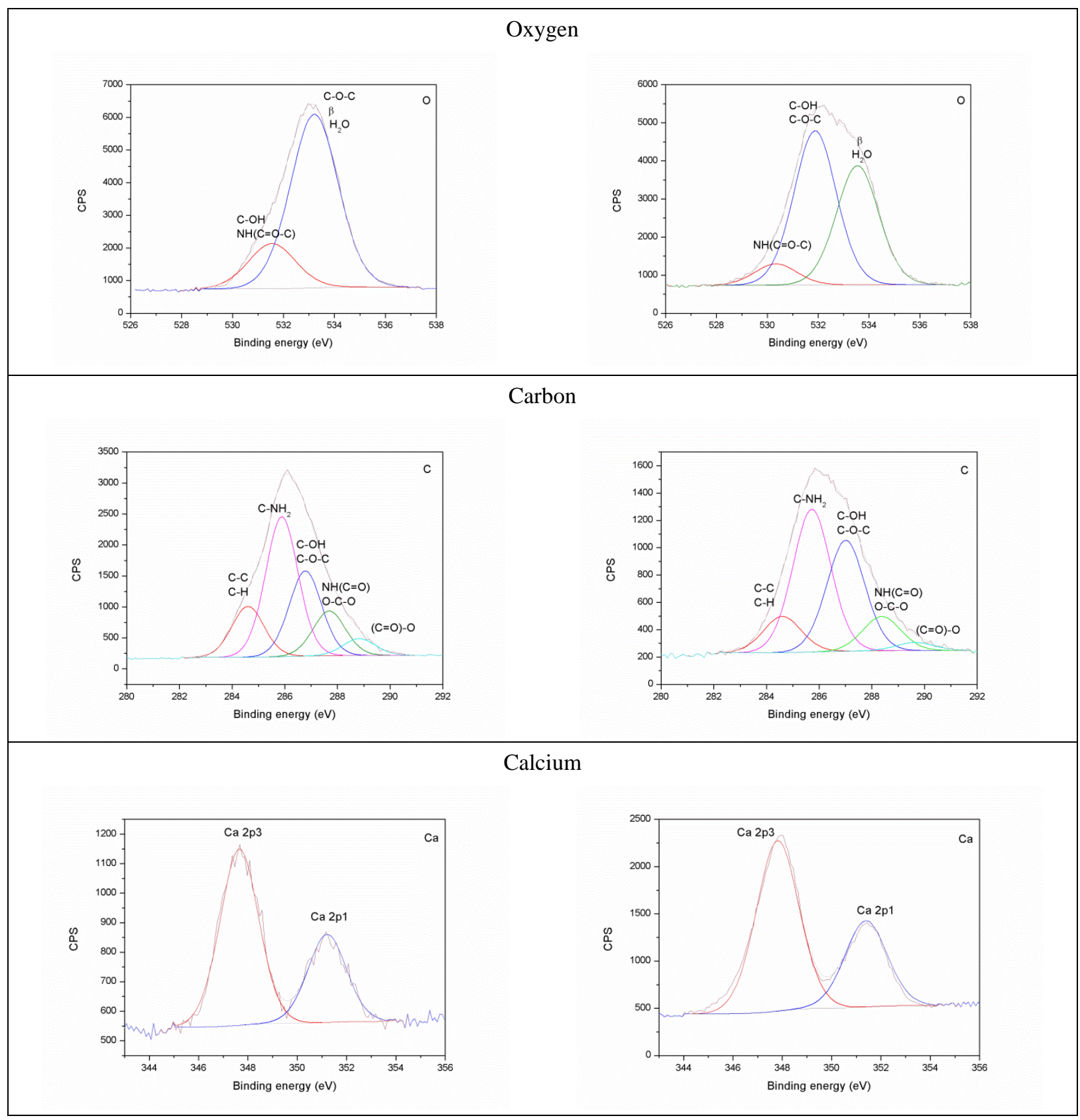

The results of the XPS analysis suggest that, after the introduction of collagen into the chitosan gel structure, the number of $\mathrm{NH}-(\mathrm{C}=\mathrm{O})-\mathrm{C}$ bonds increases, while the number of bonds $\beta(1 \rightarrow 4)$ decrease, the percentage of nitrogen slightly decreases, the percentage of carbon falls dramatically, and also the number of $\mathrm{C}-\mathrm{C}, \mathrm{C}-\mathrm{H}, \mathrm{C}-\mathrm{N}$ and $\mathrm{C}-\mathrm{OH}$ bonds decrease, while phosphorus remains unchanged. This suggests the possibility of combining collagen with chitosan and $\mathrm{C} 1$ carbon, as well as with amine groups and hydroxide.

In the case of the addition of ALP to the chitosan-collagen gel a clear decrease of $\mathrm{NH}-(\mathrm{C}=\mathrm{O})-\mathrm{C}$ can be observed which is connected with the participation of acetylamine groups in the reaction with ALP. This is confirmed by FTIR spectra where the arm at wavenumber $1700 \mathrm{~cm}^{-1}$ of amide band $1660 \mathrm{~cm}^{-1}$ disappears. After the addition of ALP, in the XPS spectra an increase of amine groups takes place - they are revealed and phosphorus disappears, so ALP 
probably conjugates the phosphate residue interacting with electrostatic interactions with amine groups; the number of $\mathrm{C}-\mathrm{C}, \mathrm{C}-\mathrm{H}$ increases, which confirm the breaking of glycosidic bonds.

After the mineralization of both chitosan gels and chitosan-collagen gels the bonds most likely break because oxygen bands corresponding to bonds $\beta(1 \rightarrow 4)$ disappear.

After the mineralization of chitosan gels containing ALP, significant changes were observed in relation to chitosan gels before the mineralization; the proportion of $\mathrm{NH}-(\mathrm{C}=\mathrm{O})-\mathrm{C}$ groups decrease, while the proportion of $\mathrm{C}-\mathrm{OH} \mathrm{C}-\mathrm{O}-\mathrm{C}$ bonds increase, also nitrogen and the number of assigned bonds $\mathrm{C}-\mathrm{N} \mathrm{C}-\mathrm{OH},(\mathrm{C}=\mathrm{O})-\mathrm{O}$ increase.

After the mineralization of chitosan-collagen gels containing ALP, significant changes in comparison with pure chitosan-collagen gels take place at the following bonds: the proportion of $\mathrm{NH}-(\mathrm{C}=\mathrm{O})-\mathrm{C}$ groups increases and $\mathrm{C}-\mathrm{OH}$ slightly increases, the percentage of $\mathrm{C}-\mathrm{C}, \mathrm{C}-\mathrm{H} \mathrm{C}-\mathrm{N}$ $\mathrm{C}-\mathrm{OH},(\mathrm{C}=\mathrm{O})-\mathrm{O}$ groups remains at the same level and the proportion of nitrogen rises; if those changes are compared with chitosan-collagen hydrogel containing ALP before mineralization, the number of $\mathrm{C}-\mathrm{C}, \mathrm{C}-\mathrm{H}$ C-N C-OH bonds significantly decrease, whereas nitrogen remains at the same level. Thus, ALP in chitosan-collagen gels is bound by $\mathrm{NH}-(\mathrm{C}=\mathrm{O})-\mathrm{C}$ groups while during the mineralization process $\mathrm{CaGP}$ was decomposed by ALP to $\mathrm{Ca}$ and $\mathrm{P}$ and disconnected from $\mathrm{NH}-(\mathrm{C}=\mathrm{O})-\mathrm{C}$ groups. Due to the fact that the spectrum of $\mathrm{O}$ and $\mathrm{C}$ of chitosan-collagen gel containing ALP after mineralization is close to the pure spectrum of chitosan-collagen gel before mineralization, the compounds of $\mathrm{Ca}$ and $\mathrm{P}$ were created in the hydrogel pores.

24-hour mineralization of chitosan-collagen gels containing ALP allows compounds of $\mathrm{Ca}$ and $\mathrm{P}$ with $\mathrm{Ca} / \mathrm{P}$ atomic ratio close to 1.0 to be obtained, while mineralization of chitosan gels containing ALP results in an atomic ratio of $\mathrm{Ca} / \mathrm{P}$ equal to approximately 0.6 .

After the mineralization in the gels containing ALP, $1.7 \%$ of Ca was obtained and $8.3 \%$

SEM images of freeze-dried hydrogels after incubation in mineralization solution after 24 hours can be seen in Figure 9.

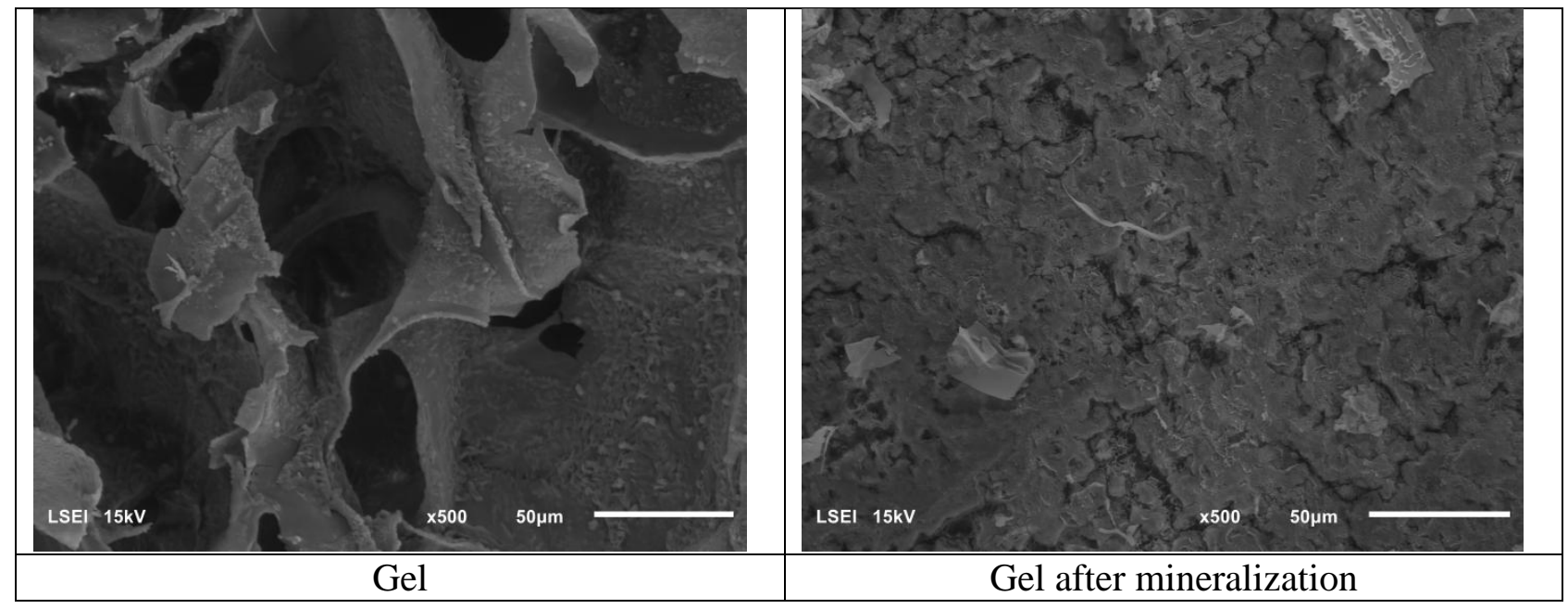




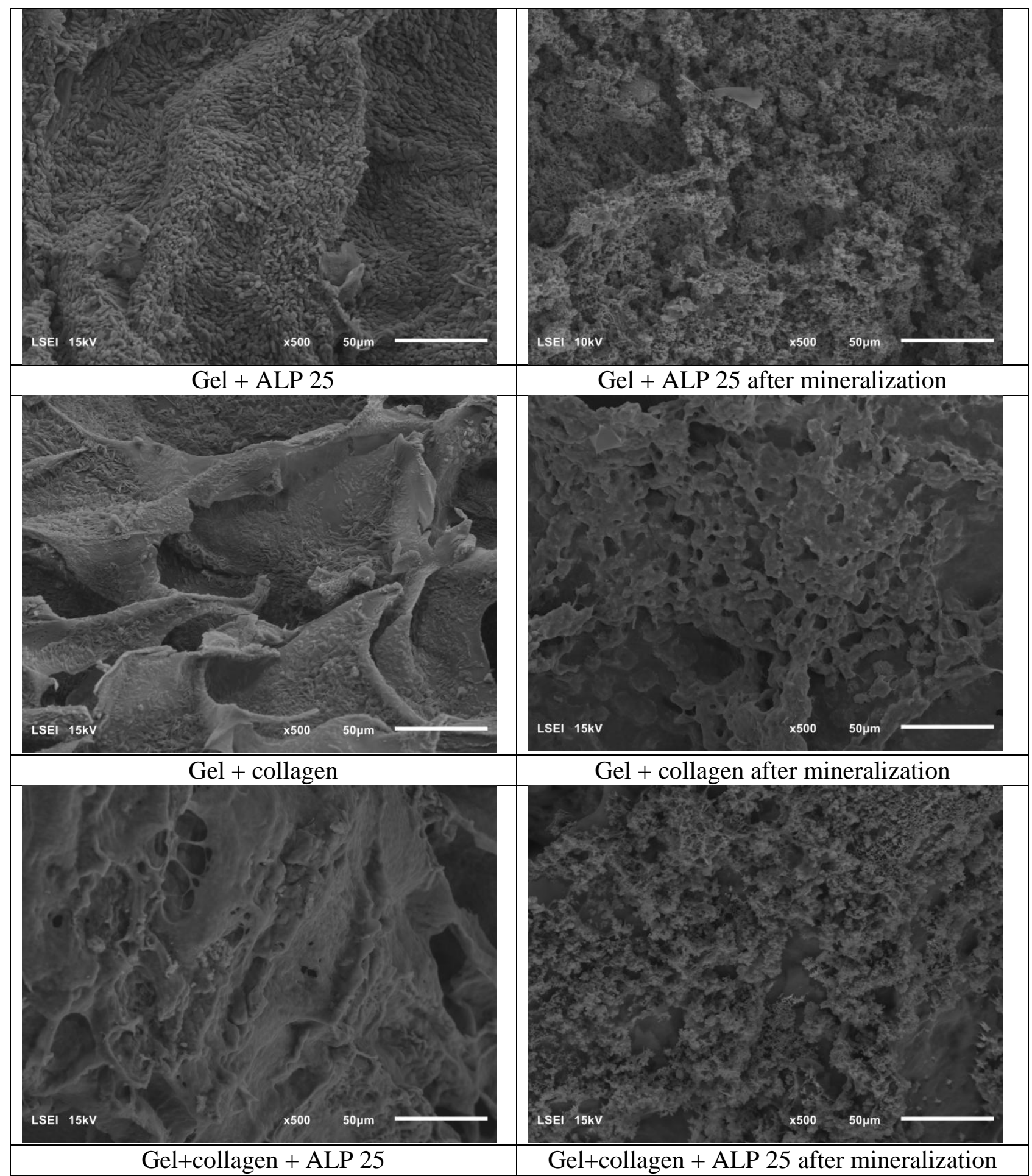

Figure 9. SEM images of the gels before and after mineralization

All samples, both containing ALP and collagen contained platelet-shaped structures. The structure of ALP containing gels is greatly expanded. However, such structures displayed different, rougher morphologies in samples containing ALP and collagen after mineralization in 
The structure of gels containing collagen and ALP are more compressed-comparison to the structure of gels without ALP. After mineralization especially, in gels containing ALP the mineral-like deposits were present.

\section{Conclusions}

Mineralization of chitosan gels and chitosan-collagen gels have a similar effect on the changes of the gel structure. The spectra indicate a very strong influence of this process on the resonant frequencies of the grouping vibrations in the whole spectrum. We observed a deformation of the band of oscillators $-\mathrm{O}-\mathrm{H}$ and $\mathrm{N}-\mathrm{H}$ and a change for bands connected with $\mathrm{C}-\mathrm{H}$ groups. This proves that significant changes in the conformation of chains and changes in the supermolecular structure of the obtained gels are taking place. Tensions in the polymer chains are revealed through an increase of resonant frequencies of $\mathrm{C}-\mathrm{O}$ groupings occurring both in the heterocyclic ring and in the oxygen bridge. They all shift towards higher vibration energies after the mineralization process.

Mineralization of chitosan-collagen gels containing ALP indicates the influence of ALP on aliphatic phosphatase and it is probably connected with a strong interaction on the N-H oscillator in the amide grouping and the creation of strong ionic bonds. An increase of ALP concentrations causes the separation of macromolecules, thus releasing them from the strong mutual deformations. The increasing ALP concentrations cause a relaxation of the polymer and shifting of the oscillation band $\mathrm{C}-\mathrm{N}$ in the amide group towards lower wavenumbers, which is revealed as an appearance of this band in the spectra. The addition of ALP does not reduce the tensions in the oxygen bridges, which is proved by the tension remaining along the chain.

The XPS analysis suggests that collagen and chitosan in a solution of hydrochloric acid is connected through $\mathrm{C} 1$ carbon, and also amine and hydroxide groups; ALP in the chitosancollagen gel reacts with $\mathrm{NH}-(\mathrm{C}=\mathrm{O})-\mathrm{C}$ groups and during the mineralization process $\mathrm{CaGP}$ was decomposed by ALP to $\mathrm{Ca}$ and $\mathrm{P}$ and disconnected from $\mathrm{NH}-(\mathrm{C}=\mathrm{O})-\mathrm{C}$ groups, hence indicated formation of amorphous calcium phosphate Conjugates of the phosphate residue interacting with amine groups, the glycosidic bonds break; compounds of calcium and phosphorus are created in the hydrogel pores.

$1.7 \%$ of calcium was obtained after the mineralization chitosan hydrogels containing ALP and $8.3 \%$ in the structure of chitosan-collagen gels containing ALP, thus it is five times more $\mathrm{Ca}$, and the $\mathrm{Ca} / \mathrm{P}$ ratio is close to that of hydroxyapatite and such chitosan hydrogel containing collagen and alkaline phosphatase may pretend for use for biomedical applications.

\section{ACKNOWLEDGEMENTS}

The research was financed by the National Science Center of Poland Grant N UMO-2013/09/N/ST8/01064.

\section{Literature}

[1] Venkatesan, J., Vinodhini, P. A., Sudha, P. N., \& Kim, S.-K. (2014). Chitin and Chitosan Composites for Bone Tissue Regeneration. Advances in Food and Nutrition Research, 5981. doi:10.1016/b978-0-12-800268-1.00005

[2] Muzzarelli, R. A. A., \& Muzzarelli, C. et.al. Chitosan Chemistry: Relevance to the Biomedical Sciences. Advances in Polymer Science, 151-209. doi:10.1007/b136820 
[3] Bojar, W., Kucharska, M., Ciach, T., Koperski, Ł., Jastrzębski, Z., \& Szałwiński, M. (2013). Bone regeneration potential of the new chitosan-based alloplastic biomaterial. Journal of Biomaterials Applications, 28(7), 1060-1068. doi:10.1177/0885328213493682

[4] Mucha, M. Michalak,I. Balcerzak, J. Tylman M.(2012). Chitosan scaffolds, films and microgranules for medical application - preparation. Polimery 2012, No 10, 714. doi:dx.doi.org/10.14314/polimery.2012.714

[5] Modrzejewska, Z. (2001). The effect of seasoning a membrane-forming solution on the separation properties of chitosan membranes. Journal of Membrane Science, 181(2), 229239. doi:10.1016/s0376-7388(00)00537-8

[6] Adamiec, J., \& Modrzejewska, Z. (2005). Some Structural Properties of Spray-Dried Chitosan Microgranules. Drying Technology, 23(8), 1601-1611. doi:10.1081/drt200064989

[7] Jung-A Shin, Jung-Yoo Choi, Sung-Tae Kim, Chang-Sung Kim, Yong-Keun Lee, KyooSung Cho, Jung-Kiu Chai, Chong-Kwan Kim, Seong-Ho Choil (2009) The Effects of Hydroxyapatite-Chitosan Membrane on Bone Regeneration in Rat Calvarial Defects. The Journal of the Korean Academy of Periodontology 39(Suppl):213222.doi:10.5051/jkape.2009.39.S.213

[8] Ehrlich, H., Krajewska, B., Hanke, T., Born, R., Heinemann, S., Knieb, C., \& Worch, H. (2006). Chitosan membrane as a template for hydroxyapatite crystal growth in a model dual membrane diffusion system. Journal of Membrane Science, 273(1-2), 124-128. doi:10.1016/j.memsci.2005.11.050

[9] Chesnutt, B. M., Yuan, Y., Buddington, K., Haggard, W. O., \& Bumgardner, J. D. (2009). Composite Chitosan/Nano-Hydroxyapatite Scaffolds Induce Osteocalcin Production by OsteoblastsIn Vitroand Support Bone FormationIn Vivo. Tissue Engineering Part A, 15(9), 2571-2579. doi:10.1089/ten.tea.2008.0054

[10] Manjubala, I., Scheler, S., Bössert, J., \& Jandt, K. D. (2006). Mineralisation of chitosan scaffolds with nano-apatite formation by double diffusion technique. Acta Biomaterialia, 2(1), 75-84. doi:10.1016/j.actbio.2005.09.007

[11] Peña, J., Izquierdo-Barba, I., Martínez, A., \& Vallet-Regí, M. (2006). New method to obtain chitosan/apatite materials at room temperature. Solid State Sciences, 8(5), 513-519. doi:10.1016/j.solidstatesciences.2005.11.0

[12] LogithKumar, R., KeshavNarayan, A., Dhivya, S., Chawla, A., Saravanan, S., \& Selvamurugan, N. (2016). A review of chitosan and its derivatives in bone tissue engineering. Carbohydrate Polymers, 151, 172-188. doi:10.1016/j.carbpol.2016.05.049

[13] Douglas, T. E. L. (2016). Biomimetic mineralization of hydrogels. Biomineralization and Biomaterials, 291-313. doi:10.1016/b978-1-78242-338-6.00010

[14] Turdean, G. L., Fort, I. C., \& Simon, V. (2015). In vitro short-time stability of a bioactive glass-chitosan composite coating evaluated by using electrochemical methods. Electrochimica Acta, 182, 707-714. doi:10.1016/j.electacta.2015.09.132

[15] Moatary, A., Teimouri, A., Bagherzadeh, M., Chermahini, A. N., \& Razavizadeh, R. (2017). Design and fabrication of novel chitin hydrogel/chitosan/nano diopside composite scaffolds for tissue engineering. Ceramics International, 43(2), 1657-1668. doi:10.1016/j.ceramint.2016.06.068

[16] Saravanan, S., Leena, R. S., \& Selvamurugan, N. (2016). Chitosan based biocomposite scaffolds for bone tissue engineering. International Journal of Biological Macromolecules, 93, 1354-1365. doi:10.1016/j.ijbiomac.2016.01.112 
[17]Huang, Z.-H., Dong, Y.-S., Chu, C.-L., \& Lin, P.-H. (2008). Electrochemistry assisted reacting deposition of hydroxyapatite in porous chitosan scaffolds. Materials Letters, 62(19), 3376-3378. doi:10.1016/j.matlet.2008.03.045

[18] Thein-Han, W. W., \& Misra, R. D. K. (2009). Biomimetic chitosan-nanohydroxyapatite composite scaffolds for bone tissue engineering. Acta Biomaterialia, 5(4), 1182-1197. doi:10.1016/j.actbio.2008.11.025

[19] Kona, S., Wadajkar, A. S., \& Nguyen, K. T. (2011). Tissue engineering applications of injectable biomaterials. Injectable Biomaterials, 142-182. doi:10.1533/9780857091376.2.142

[20] Kong, L., Gao, Y., Lu, G., Gong, Y., Zhao, N., \& Zhang, X. (2006). A study on the bioactivity of chitosan/nano-hydroxyapatite composite scaffolds for bone tissue engineering. European Polymer Journal, 42(12), 3171-3179. doi:10.1016/j.eurpolymj.2006.08.009

[21] Hu, Q. (2004). Preparation and characterization of biodegradable chitosan/hydroxyapatite nanocomposite rods via in situ hybridization: a potential material as internal fixation of bone fracture. Biomaterials, 25(5), 779-785. doi:10.1016/s0142-9612(03)00582-9

[22] Yang, B., Li, X., Shi, S., Kong, X., Guo, G., Huang, M., ... Qian, Z. (2010). Preparation and characterization of a novel chitosan scaffold. Carbohydrate Polymers, 80(3), 860-865. doi:10.1016/j.carbpol.2009.12.044

[23] Huang, Z.-H., Dong, Y.-S., Chu, C.-L., \& Lin, P.-H. (2008). Electrochemistry assisted reacting deposition of hydroxyapatite in porous chitosan scaffolds. Materials Letters, 62(19), 3376-3378. doi:10.1016/j.matlet.2008.03.045

[24] Haruhiko, K. Yusuke, K. Atsushi, M. (2009) PressFabrication of porouschitosan/hydroxyapatite nanocomposites:Their mechanical and biological properties Bio-Medical Materials and Engineering 19 133-140133 doi:10.3233/BME-2009-0572IOS

[25] Kong, L., Gao, Y., Lu, G., Gong, Y., Zhao, N., \& Zhang, X. (2006). A study on the bioactivity of chitosan/nano-hydroxyapatite composite scaffolds for bone tissue engineering. European Polymer Journal, 42(12), 3171-3179. doi:10.1016/j.eurpolymj.2006.08.009

[26] Hu, Q. (2004). Preparation and characterization of biodegradable chitosan/hydroxyapatite nanocomposite rods via in situ hybridization: a potential material as internal fixation of bone fracture. Biomaterials, 25(5), 779-785. doi:10.1016/s0142-9612(03)00582-9

[27] Yang, B., Li, X., Shi, S., Kong, X., Guo, G., Huang, M., ... Qian, Z. (2010). Preparation and characterization of a novel chitosan scaffold. Carbohydrate Polymers, 80(3), 860-865. doi:10.1016/j.carbpol.2009.12.044

[28] Drury, J. L., \& Mooney, D. J. (2003). Hydrogels for tissue engineering: scaffold design variables and applications. Biomaterials, 24(24), 4337-4351. doi:10.1016/s01429612(03)00340-5

[29] Singh, M. R., Patel, S., \& Singh, D. (2016). Natural polymer-based hydrogels as scaffolds for tissue engineering. Nanobiomaterials in Soft Tissue Engineering, 231-260. doi:10.1016/b978-0-323-42865-1.00009-

[30] Ward, M. A., \& Georgiou, T. K. (2011). Thermoresponsive Polymers for Biomedical Applications. Polymers, 3(3), 1215-1242. doi:10.3390/polym3031215

[31] Costa-Pinto, A. R., Reis, R. L., \& Neves, N. M. (2011). Scaffolds Based Bone Tissue Engineering: The Role of Chitosan. Tissue Engineering Part B: Reviews, 17(5), 331-347. doi:10.1089/ten.teb.2010.0704 
[32] Sivashanmugam, A., Arun Kumar, R., Vishnu Priya, M., Nair, S. V., \& Jayakumar, R. (2015). An overview of injectable polymeric hydrogels for tissue engineering. European Polymer Journal, 72, 543-565. doi:10.1016/j.eurpolymj.2015.05.014

[33] Liu, M., Zeng, G., Wang, K., Wan, Q., Tao, L., Zhang, X., \& Wei, Y. (2016). Recent developments in polydopamine: an emerging soft matter for surface modification and biomedical applications. Nanoscale, 8(38), 16819-16840. doi:10.1039/c5nr09078d

[34] Liu, Y., Ai, K., \& Lu, L. (2014). Polydopamine and Its Derivative Materials: Synthesis and Promising Applications in Energy, Environmental, and Biomedical Fields. Chemical Reviews, 114(9), 5057-5115. doi:10.1021/cr400407a

[35] Huang, L., Liu, M., Huang, H., Wen, Y., Zhang, X., \& Wei, Y. (2018). Recent Advances and Progress on Melanin-like Materials and Their Biomedical Applications. Biomacromolecules, 19(6), 1858-1868. doi:10.1021/acs.biomac.8b00437

[36] Shi, Y., Jiang, R., Liu, M., Fu, L., Zeng, G., Wan, Q., ... Wei, Y. (2017). Facile synthesis of polymeric fluorescent organic nanoparticles based on the self-polymerization of dopamine for biological imaging. Materials Science and Engineering: C, 77, 972-977. doi:10.1016/j.msec.2017.04.033

[37] Huang, Q., Liu, M., Chen, J., Wan, Q., Tian, J., Huang, L., ... Wei, Y. (2017). Facile preparation of MoS 2 based polymer composites via mussel inspired chemistry and their high efficiency for removal of organic dyes. Applied Surface Science, 419, 35-44. doi:10.1016/j.apsusc.2017.05.006

[38] Liu, M., Ji, J., Zhang, X., Zhang, X., Yang, B., Deng, F., ... Wei, Y. (2015). Selfpolymerization of dopamine and polyethyleneimine: novel fluorescent organic nanoprobes for biological imaging applications. Journal of Materials Chemistry B, 3(17), 3476-3482. doi:10.1039/c4tb02067g

[39]Zhang, X., Huang, Q., Liu, M., Tian, J., Zeng, G., Li, Z., ... Wei, Y. (2015). Preparation of amine functionalized carbon nanotubes via a bioinspired strategy and their application in Cu2+ removal. Applied Surface Science, 343, 19-27. doi:10.1016/j.apsusc.2015.03.081

[40] Sander, C. Leeuwenburgh, G. Douglas, T. E. L. Jansen, J. A. Skwarczynska, A. Modrzejewska, Z. (2013). Chitosan-based hydrogels containing enzyme alkaline phosphatase, Patent WO 2013/015688 A1

[41] Douglas, T. E. L., Skwarczynska, A., Modrzejewska, Z., Balcaen, L., Schaubroeck, D., Lycke, S., ... Leeuwenburgh, S. C. G. (2013). Acceleration of gelation and promotion of mineralization of chitosan hydrogels by alkaline phosphatase. International Journal of Biological Macromolecules, 56, 122-132. doi:10.1016/j.ijbiomac.2013.02.002

[42] Douglas, T. E. L. Krok-Borkowicz, M. Macuda, A. Pietryga, K. Pamula, E. (2016). Enrichment of thermosensitive chitosan hydrogels with glycerol and alkaline phosphatase for bone tissue engineering applications. Acta of Bioengineering and Biomechanics 18, 51 57.

[43] Ma, X., He, Z., Han, F., Zhong, Z., Chen, L., \& Li, B. (2016). Preparation of collagen/hydroxyapatite/alendronate hybrid hydrogels as potential scaffolds for bone regeneration. Colloids and Surfaces B: Biointerfaces, 143, 81-87. doi:10.1016/j.colsurfb.2016.03.025

[44] Yamauchi, K. (2004). Preparation of collagen/calcium phosphate multilayer sheet using enzymatic mineralization. Biomaterials, 25(24), 5481-5489.

doi:10.1016/j.biomaterials.2003.12.057 
[45] Soares, D. G., Rosseto, H. L., Basso, F. G., Scheffel, D. S., Hebling, J., \& Costa, C. A. De S. (2016). Chitosan-collagen biomembrane embedded with calcium-aluminate enhances dentinogenic potential of pulp cells. Brazilian Oral Research, 30(1). doi:10.1590/18073107bor-2016.vol30.0054

[46] Skwarczynska, A. L. Binias, D. Modrzejewska, Z. (2016) Structural research of thermosensitive chitosan-collagen gels containing ALP, Progress on Chemistry and Application of Chitin and its Derivatives 21, 176-186. doi:10.15259/PCACD.21.19

[47] Chenite, A., Chaput, C., Wang, D., Combes, C., Buschmann, M. ., Hoemann, C. ., Selmani, A. (2000). Novel injectable neutral solutions of chitosan form biodegradable gels in situ. Biomaterials, 21(21), 2155-2161. doi:10.1016/s0142-9612(00)00116-2

[48] De Campos Vidal, B., \& Mello, M. L. S. (2011). Collagen type I amide I band infrared spectroscopy. Micron, 42(3), 283-289. doi:10.1016/j.micron.2010.09.010

[49] De La Fournière, L., Nosjean, O., Buchet, R., \& Roux, B. (1995). Thermal and pH stabilities of alkaline phosphatase from bovine intestinal mucosa: a FTIR study. Biochimica et Biophysica Acta (BBA) - Protein Structure and Molecular Enzymology, 1248(2), 186-192. doi:10.1016/0167-4838(95)00020-u

[50] Lendl, B., Krieg, P., \& Kellner, R. (1998). Determination of alkaline phosphatase activity in human sera by mid-FTIR spectroscopy. Fresenius' Journal of Analytical Chemistry, 360(6), 717-720. doi:10.1007/s002160050788 


\section{HIGHLIGHTS}

- $\quad$ Chitosan hydrogels containing ALP and collagen have been prepared

- $\quad$ Results before and after mineralization are compared, showing clear differences

- $\quad$ Apatite-like mineral within chitosan hydrogels after mineralization were discussed 


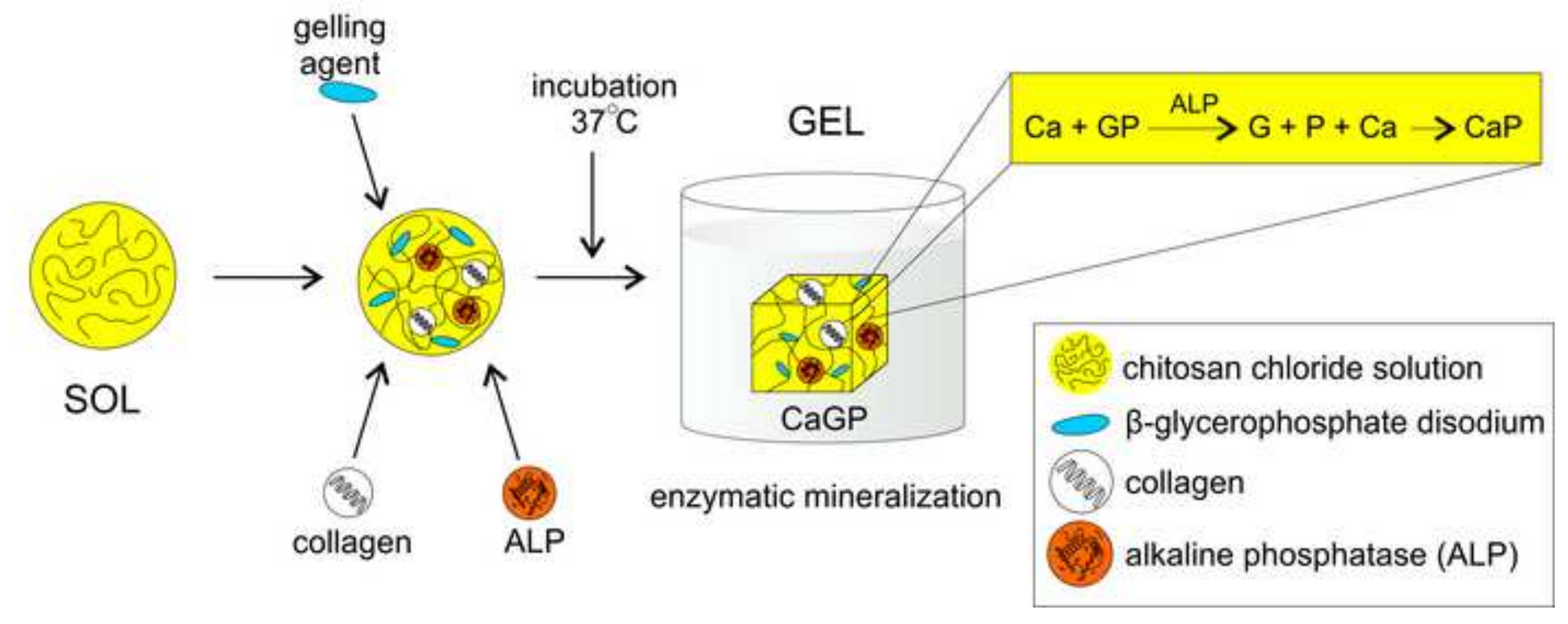

gelling 